\title{
Determinants of emissions pathways in the coupled climate-social system
}

https://doi.org/10.1038/s41586-022-04423-8

Received: 28 July 2021

Accepted: 12 January 2022

Published online: 16 February 2022

Check for updates

\author{
Frances C. Moore ${ }^{1 凶}$, Katherine Lacasse $^{2}$, Katharine J. Mach ${ }^{3,4}$, Yoon Ah Shin ${ }^{5}$, Louis J. Gross ${ }^{6,7}$ \\ \& Brian Beckage ${ }^{8,9,10}$
}

The ambition and effectiveness of climate policies will be essential in determining greenhouse gas emissions and, as a consequence, the scale of climate change impacts $^{1,2}$. However, the socio-politico-technical processes that will determine climate policy and emissions trajectories are treated as exogenous in almost all climate change modelling ${ }^{3,4}$. Here we identify relevant feedback processes documented across a range of disciplines and connect them in a stylized model of the climate-social system. An analysis of model behaviour reveals the potential for nonlinearities and tipping points that are particularly associated with connections across the individual, community, national and global scales represented. These connections can be decisive for determining policy and emissions outcomes. After partly constraining the model parameter space using observations, we simulate 100,000 possible future policy and emissions trajectories. These fall into 5 clusters with warming in 2100 ranging between $1.8^{\circ} \mathrm{C}$ and $3.6^{\circ} \mathrm{C}$ above the $1880-1910$ average. Public perceptions of climate change, the future cost and effectiveness of mitigation technologies, and the responsiveness of political institutions emerge as important in explaining variation in emissions pathways and therefore the constraints on warming over the twenty-first century.
The global trajectory of anthropogenic greenhouse gas emissions is the most important determinant of projected global temperature increases in this century and beyond, swamping the magnitude of internal climate variability or model differences ${ }^{1}$. However, this key driver of Earth's future climate is treated as exogenous in almost all climate science ${ }^{3}$. Moreover, although emissions pathways arise from complex interactions among social, political, economic and technical systems, these elements are often analysed separately within disciplinary silos, neglecting interactions and feedback that can give rise to or stymie rapid change ${ }^{5}$. Understanding the potential for nonlinear dynamics in the socio-technical systems producing both greenhouse gases and climate policy is essential for identifying high-impact intervention points and better informing policy ${ }^{4,6,7}$. However, the coupling and interaction among social, political, economic, technical and climate systems-and their implications for emissions and temperature trajectories over the twenty-first century-have not been widely examined (although refs. ${ }^{2,8,9}$ provide some exceptions).

Evidence regarding the likely emissions path over the twenty-first century is mixed. On the one hand, although emissions growth may have decelerated in recent years, with some evidence of declining emissions in a few advanced economies, global emissions continue to grow ${ }^{10}$. National commitments under the Paris Agreement remain inadequate to meet either the $1.5^{-} \mathrm{C}$ or $2^{-}{ }^{\circ} \mathrm{C}$ temperature target ${ }^{11}$ and it is unclear whether government policies are yet sufficient to deliver on these emissions pledges ${ }^{12}$. Carbon dioxide emissions from energy infrastructure currently in place or under development will exceed the $1.5-^{\circ} \mathrm{C}$ carbon budget, and standard energy-system models struggle to simulate pathways that meet either temperature target without the widespread deployment of negative emissions technologies that are highly speculative $\mathrm{e}^{13-15}$. The pace of decarbonization that is required to meet the Paris temperature targets vastly exceeds anything in the historical record at the global scale ${ }^{16}$.

On the other hand, specific cases of very rapid change in energy systems do exist, with accelerating deployment as market or policy conditions shift and technology costs fall. Path dependencies, increasing returns to scale and learning-by-doing cost reductions can produce sudden, tipping-point-like transitions that cannot be extrapolated from past system behaviour ${ }^{17,18}$. Recent examples include the rapid fall in coal generation in the UK electricity mix and the dominance of electric vehicles sales in Norway ${ }^{19,20}$. Standard energy models, which mostly rely on linear extrapolations of past behaviour, repeatedly underpredict the rate of renewable energy growth ${ }^{21}$. Historically, technological innovation and government policies often motivated by energy security concerns ${ }^{22}$ have also, in notable cases, spurred rapid shifts in energy systems, one of the fastest examples of which being the transition to kerosene lighting in the nineteenth century ${ }^{23}$.

Social norms that shape individual behaviour and preferences can exhibit similar tipping-point style dynamics ${ }^{24}$. These changes,

'Department of Environmental Science and Policy, University of California, Davis, CA, USA. ${ }^{2}$ Department of Psychology, Rhode Island College, Providence, RI, USA. ${ }^{3}$ Department of Environmental Science and Policy, Rosenstiel School of Marine and Atmospheric Science, University of Miami, Miami, FL, USA. ${ }^{4}$ Leonard and Jayne Abess Center for Ecosystem Science and Policy, University of Miami, Miami, FL, USA. ${ }^{5}$ Global Futures Laboratory, Arizona State University, Tempe, AZ, USA. ${ }^{6}$ Department of Ecology and Evolutionary Biology, University of Tennessee, Knoxville, TN, USA. ${ }^{7}$ Department of Mathematics, University of Tennessee, Knoxville, TN, USA. ${ }^{8}$ Department of Plant Biology, University of Vermont, Burlington, VT, USA. ${ }^{9}$ Department of Computer Science, University of Vermont, Burlington, VT, USA. ${ }^{10}$ Gund Institute for Environment, University of Vermont, Burlington, VT, USA. ${ }^{凶} \mathrm{e}-\mathrm{mail}$ : fmoore@ucdavis.edu 
via collective action operating though political institutions, could in turn affect the regulatory and market conditions in which energy technologies compete. The presence of both positive and negative feedback processes within the political system has also been documented, as policy changes can both create new interest groups and activate incumbents against further change $\mathrm{e}^{25-27}$.

These coupled feedback processes could give rise to complex behaviour and a wide range of plausible emissions pathways but, although the space of possibility is wide, that does not mean it is unknowable. Our goal is to model the drivers of potential emissions scenarios over the twenty-first century and, in doing so, shed light on how both climate policy and emissions arise from more fundamental socio-politico-technical forces and the key parameters governing these dynamics.

The main contributions are threefold. First, we present a stylized model of the coupled climate-social system, focusing on coupling across individual to global scales and on feedback processes documented across a wide range of relevant disciplinary literatures. This model is distinct from previous work that represents feedback processes within energy system ${ }^{28}$ or between the climate, the economy and emissions pathways ${ }^{29}$ in that climate policy is still specified exogenously in these applications. By contrast, in this model, climate policy and greenhouse gas emissions arise endogenously from the coupled interaction of the climate, social, political and energy systems.

Second, we used this model to systematically examine potential dynamics of the system, highlighting feedback, connections and thresholds across different components. Finally, after partially constraining the set of parameter values using historical data, we examined the space of possible emissions and policy trajectories over the twenty-first century arising from the model. These fall into five clusters associated with particular parameter combinations, enabling these future trajectories to be classified on the basis of their underlying social, political and technical characteristics. Overall, we find that the socio-politico-technical feedback processes can be decisive determinants of climate policy and emissions futures. Our parameterized model implies a high likelihood of accelerating emissions reductions over the twenty-first century, moving the world decisively away from a no-policy, business-as-usual baseline.

\section{Feedback and model structure}

The positive and negative feedback processes operating within the coupled climate-social system are critical to understanding system behaviour and dynamics. The feedback processes that are represented in the model were identified in a two-step process. First, potentially relevant system feedback processes were described during a four-day interdisciplinary workshop. Second, targeted searches were conducted across relevant literatures in psychology, economics, sociology, law, political science and engineering to evaluate the evidentiary literature for or against candidate feedback processes, resulting in eight key feedback processes being included in the final model. This section briefly describes each feedback process, and Table 1 and Fig. 1 describe how these feedback processes are coupled together in the model and the model structure.

\section{Social-conformity feedback}

The social networks in which individuals are embedded at home, work, school or leisure have a strong influence on opinions and behaviour ${ }^{30,31}$. Social norms (that is, representations of the dominant or acceptable practices or opinions within a social group) are costly for individuals to violate and, over the long term, can shape individual identities, habits and world-views ${ }^{32,33}$. Studies in the USA have shown that perceived social consensus, that is, the degree to which individuals believe a particular opinion or action is dominant within their social group, can partially explain belief in climate change and support for climate policies $^{34}$. A large body of literature has also shown that social norms are one important determinant of the probability that an individual engages in pro-environmental behaviour, such as conserving energy or adopting solar panels ${ }^{35-37}$. A tendency towards social conformity can lead to tipping-point-type dynamics in which a system transitions suddenly from a previously stable state given a sufficient critical mass of proponents of the alternate norm ${ }^{24,38}$. The model includes the social conformity effect in two ways: formation of public opinion regarding climate policy and individual decisions on adopting pro-climate behaviour (Fig. 1).

\section{Climate change perception feedback}

The anthropogenic influence on the Earth's climate system is increasingly apparent ${ }^{39-41}$. Assessments of the contribution of anthropogenic warming to the probability of particular extreme events are increasingly routine ${ }^{42}$. It has been hypothesized that this emerging signal of climate change in people's everyday experience of weather might lead to widespread acknowledgement of the existence of global warming and possibly, by extension, support for mitigation policy ${ }^{43}$. A large number of studies have connected stated belief in global warming with local temperature anomalies: people appear to be able to identify local warming ${ }^{44,45}$ and are more likely to report believing in climate change if the weather is (or is perceived to be) unusually warm ${ }^{46-49}$. In effect, people appear to be using their personal experience of weather as evidence informing their belief in climate change ${ }^{49}$.

However, this so-called 'local warming effect' is complicated ${ }^{50}$. Several papers have found evidence that interpretations of weather events are filtered through pre-existing partisan identities or ideologies $^{45,51,52}$. This suggests the presence of motivated reasoning (that is, the rejection of new information that contradicts pre-existing beliefs) in the processing of climate-change-related information ${ }^{53,54}$. Moreover, the perception of weather anomalies might well be complicated by a 'shifting-baselines' effect in which people's perception of normal conditions is quickly updated on the basis of recent experience of weather ${ }^{55}$.

\section{Political interest feedback}

The large-scale emissions reductions that are required to stabilize the climate system cannot be accomplished by individuals acting alone, meaning the question of how individual support or opposition to climate policy translates into collective action through the political system is critical. This process is not straightforward-it is subject to political-economic constraints operating through complex political and government institutions and cannot be modelled as a simple linear function of public opinion ${ }^{56-58}$. The political economy literature has documented a positive feedback effect in which initial policy change establishes powerful interests able to lobby against policy reversal and for further change, the establishment of the wind energy industry in Texas being one example ${ }^{26,27}$. Although most examples in the literature are ones of reinforcing feedback processes, Stoke $^{27}$ also documents instances of balancing feedback processes-where small policy changes activate powerful incumbents to lobby against further changes that threaten their interests.

\section{Credibility-enhancing display feedback}

Although the ability of individuals to alter the trajectory of greenhouse gas emissions is limited, individual adoption of pro-environmental behaviours can have spillover effects to the larger social network. Changing behaviour to better align one's consumption or practices with how one believes society ought to function can strengthen this moral identity and send a normative signal to other community members about desirable collective outcomes ${ }^{59,60}$. Engaging in costly personal actions aligned with collective goals can act as 'credibility enhancing displays', increasing the persuasiveness of the actor. Kraft-Todd et al. ${ }^{61}$ use this framework to explain why community ambassadors promoting solar panel installation were more effective if they had installed solar themselves. For climate change more generally, Attari, Krantz and 


\section{Table 1 | Description of the climate-social model components and key parameters}

\begin{tabular}{|c|c|}
\hline $\begin{array}{l}\text { Model } \\
\text { component }\end{array}$ & Description \\
\hline Opinion & $\begin{array}{l}\text { The opinion component models the dynamics of public } \\
\text { opinion on climate policy through changes in the fraction } \\
\text { the population falling into one of three groups: supportive } \\
\text { neutral or opposed to climate policy. Movement between } \\
\text { groups depends on social conformity (people tend toward } \\
\text { opinions common in their social group) and can, dependir } \\
\text { on parameter values, also be affected by } \\
\text { (1) observation of climate change (through the climate } \\
\text { change perception feedback); } \\
\text { (2) policy changes (through the expressive force of law } \\
\text { feedback); and (3) adoption behaviour (through the } \\
\text { credibility-enhancing display feedback). }\end{array}$ \\
\hline
\end{tabular}

Adoption The adoption component models the fraction of each opinion group adopting a single, representative pro-climate behaviour. Adoption depends on adoption cost and a desire to conform to typical behaviour within the social network (that is, a social-conformity feedback). Adoption cost can be lowered by policy and can also include an endogenous cost-reduction feedback (that is, more adopters decreases adoption cost). Adoption can also be influenced by opinion on climate policy.

Policy The policy component models collective climate change action through a single stock variable representing an effective carbon price (or subsidy for negative values). The change in policy each period depends on the distribution of climate policy opinion in the population.

Emissions The emissions component models reductions in emissions from an RCP7 no-policy baseline as a function of climate policy and individual adoption. Emissions under RCP7 are higher than expected given current climate policies, but are a more central estimate of no-policy emissions trajectories than the 'worst-case' RCP8.5 scenario ${ }^{91}$. Policy is allowed to produce persistent (that is, cumulative) emissions reductions consistent with changes to long-lived capital, while individual adoption produces non-cumulative emissions reductions. The component allows for an endogenous technical change feedback for the policy-induced mitigation. The policy component is assumed to represent the OECD and the rest of the world follows the same emissions-reduction path with some time lag (that is, consistent with principles of common but differentiated responsibility in international climate agreements). Emissions are further affected by warming levels through the temperature-emissions feedback.

\section{Key parameter Description}

Network homophily

The tendency of the population to preferentially affiliate with groups with similar opinions ${ }^{87-89}$. High network homophily means that groups with different opinions are less likely to come into contact with each other, causing divergence between policy opinions across the population and within a typical individual's social network. This parameter also defines the social network structure within the adoption component.

\begin{tabular}{ll}
\hline Persuasive force & The strength of the social-conformity effect. \\
\hline Evidence effect & $\begin{array}{l}\text { How strongly perceived climate change affects climate } \\
\text { policy opinion. }\end{array}$
\end{tabular}

Policy-opinion effect The strength of the expressive force of law feedback.

Credibility-enhancing The strength of credibility-enhancing display feedback, display effect which modifies the persuasive force for climate policy supporters that adopt individual pro-climate behaviour.

Social-norm effect The strength of the influence of social norms on adoption decisions. The social network depends on the network-homophily parameter in the same way as in the opinion component.

Opinion-adoption A parameter that describes how climate policy opinion effect affects adoption. Greater values make climate policy supporters more likely, and policy opposers less likely, to adopt for a given adoption cost.

Endogenous technical The endogenous technical change effect controls how change effect adoption costs fall with increased adoption.

Policy-adoption effect How changes in climate policy affect adoption costs.

Status quo bias The tendency of political institutions to maintain the status quo ${ }^{90}$. Higher values require larger majorities in favour of a policy change before policy responds and slows the rate of change. The effect is symmetric for increases and decreases in the carbon price.

Political interest The strength of the political interest feedback, in which past feedback policy change modifies the status quo bias parameter to make future change easier or harder. Can be a balancing feedback (that is, past changes in one direction make future change in that direction harder) or a reinforcing feedback.

Maximum mitigation Cumulative, policy-induced mitigation is modelled rate and time as a contemporaneous drop in emissions that decays exponentially over time. Both the initial drop and the rate of decay increase with more stringent climate policy. These parameters cap the maximum value that they can take as policy increases, in the absence of the learning-by-doing feedback.

Learning-by-doing The learning-by-doing effect controls the strength of the effect endogenous cost-reduction feedback for policy-induced mitigation.

Lag time This parameter controls the number of years lag between OECD policy change and the rest of the world. A value of 0 enables the model to function as a single-region model.

Adoption Effectiveness of individual pro-climate behaviour change in effectiveness reducing emissions.

Temperature- $\quad$ Feedback from warming to greenhouse gas emissions, emissions feedback parameterized on the basis of Woodard et al. .

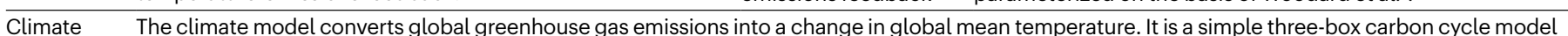
(atmosphere, upper ocean and lower ocean) and two-box temperature model (atmosphere and ocean). The structure of the model is similar to that used in the DICE integrated assessment mode ${ }^{92}$, but using annual time steps following Cai and Lontzek ${ }^{93}$. The climate model functions in the analysis only to input temperature change to the cognition component. As it is not of direct interest to the socio-politico-technical feedback processes analysed in this Article, climate model parameters are not varied in the analysis.

Cognition The cognition component converts changes in temperature Shifting-baselines Whether perceived weather anomalies are based on a fixed into perceived evidence for or against climate change. effect Weather anomalies in each time period depend on the climate and a random component based on the Earth's natural climate variability. The component allows for two cognitive biases in individuals' perceptions of climate change-shifting baselines and biased assimilation. baseline (that is, relative to the 1900 baseline of the climate model) or a shifting baseline that changes over time. This is a binary (that is, on/off) parameter. If on, anomalies are based on a weighted average of the past 8 years, with weights as in Moore et al. 55

Biased-assimilation The strength of the effect that determines how perceived effect anomalies are converted into evidence for or against climate change. High values of this parameter cause policy supporters to over-weight warm temperature anomalies and under-weight cool anomalies as evidence for or against climate change, with an opposite effect for the opposing opinion group. 


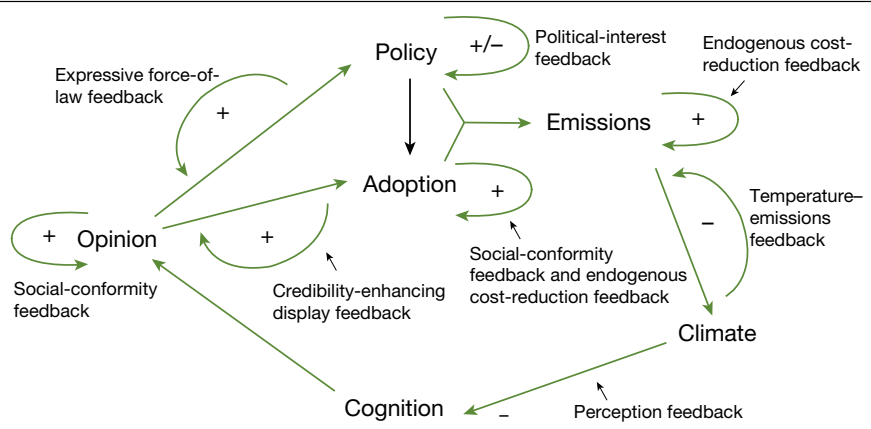

Fig. 1 | The climate-social model components and feedback processes. Components are shown in black and the model feedback processes in green. Feedback processes are identified as positive (+) (that is, reinforcing) or negative (-) (that is, dampening). The black arrow shows a connection between components (policy-adoption effect) that is not directly part of a particular feedback process. Descriptions of the components and key parameters governing both feedback strength and component behaviour are given in Table1.

Weber ${ }^{62,63}$ found that the personal carbon footprints of researchers advocating climate policy affects their credibility and the impact of their message.

\section{Expressive force of law feedback}

To the extent legal or judicial institutions are perceived as legitimate, changes in laws coming out of them can provide information about desirable or common attitudes within the population, feeding back to reinforce the attitudes or behaviour of the society that produced them. Tankard and Paluck ${ }^{64}$ identify signals from governing institutions as one of three sources of information about community norms. Legal scholars have developed the theory of the 'expressive function' of law-the idea that law and regulation work on society not only by punishing undesirable behaviour but also by signalling what kind of behaviour is praiseworthy and what is reprehensible $e^{65-67}$. This signal is particularly important if individuals have imperfect information about the distribution of attitudes or behaviour within a reference population $^{67,68}$. Several papers have found evidence for feedback from changes in laws and regulations to the perception of social norms, attitudes or behaviour, including the legalization of gay marriage $e^{69,70}$, smoking bans ${ }^{71}$ and the COVID-19 lockdowns ${ }^{72}$.

\section{Endogenous cost-reduction feedback}

New energy technologies are often expensive, but also tend to exhibit price declines with installed capacity. This 'learning-by-doing' effect has been widely documented in the energy systems literature and is incorporated into some energy system models ${ }^{73}$. Falling costs are attributed to the combination of economies of scale, lower input costs and efficiencies in the production process and design ${ }^{74}$. This is a reinforcing feedback process, where small initial deployments, possibly driven by subsidies or regulatory requirements, lower costs and enable further deployment. Rubin et al. ${ }^{75}$ reviewed estimated learning rates (that is, the fractional reduction in cost for a doubling of installed capacity) for 11 generation technologies and found ranges between $-11 \%$ and $47 \%$ with many estimates falling in the $2 \%$ to $20 \%$ range.

\section{Temperature-emissions feedback}

The effects of climate change are expected to be widely felt across geographical regions and economic sectors. These impacts themselves might well affect the capacity of the economy to produce emissions. Most notably, some work has suggested large effects of warming on economic growth ${ }^{76,77}$, which could substantially reduce the level of economic production over time with a corresponding reduction in greenhouse gas emissions. However, other effects through the impact of warming on energy demand ${ }^{78}$ or on the carbon intensity of energy production ${ }^{79,80}$ might either partially offset or exacerbate this effect. Woodard et al. ${ }^{8}$ provide a central estimate of these combined effects of a $3.1 \%$ decline in emissions per degree of warming, with upper and lower bounds ranging from $-10.2 \%$ to $0.1 \%$.

The model developed here is designed to investigate the complex, emergent behaviour of the coupled climate-social system, including the feedback processes described above. Figure 1 shows the six major model components that operate across four interconnected scales: individual (cognition component), social (opinion and adoption components), national (policy component) and global (emissions and climate components). Descriptions of processes and key parameters in each component are given in Table 1 , and equations and parameters are fully documented in the Methods and the 'Model documentation' section of the Supplementary Information.

\section{Tipping points, interactions and thresholds}

The coupled feedback processes across model components described above can produce complex, highly nonlinear behaviour that depends sensitively on interactions across social, political and technical systems. We begin by demonstrating this behaviour through three systematic explorations of the model parameter space, designed to highlight interactions across scales and model components. These values were chosen deliberately to highlight tipping-point and threshold behaviour in the model and are not necessarily the most likely or representative values. Constraints on the distribution of parameter values are discussed in the next section. Each panel in Fig. 2 shows model output, systematically varying 2-3 parameters while keeping all of the other model parameters fixed at the values given in Extended Data Table 1.

Individual behavioural change. Figure 2a demonstrates the potential for tipping points associated with individuals' adoption of behavioural change. The primary effect of behaviour change on emissions is small, reflecting the limited control that individuals have over how societies produce and use energy. The COVID-19 lockdowns, a global and unprecedented change in mobility and consumption patterns, temporarily reduced global $\mathrm{CO}_{2}$ emissions by somewhere between $9 \%$ and $17 \%$ (refs. ${ }^{81,82}$ ), providing a possible upper bound on the effect of behavioural change on reducing carbon footprints. As emissions under our RCP7 baseline almost double by 2100 , this is clearly insufficient to provide the deep decarbonization needed to stabilize global temperatures, even under universal adoption.

However, Fig. 2a demonstrates that, under some conditions, the willingness of climate policy supporters to undertake costly personal pro-climate behavioural change can be decisive in triggering positive feedback processes that tip the system into a sustainable state. This interaction operates through the credibility-enhancing display feedback from adoption to opinion; if this feedback is small or absent, then no amount of individual action can drive major emissions reduction. However, if this feedback is strong, then behavioural change by climate policy supporters persuades more people to support climate policy, an effect that triggers a cascade of positive feedback processes in the opinion (social-conformity feedback) and mitigation (learning by doing) components that drive emissions to zero by 2100 .

Learning by doing. Figure $2 \mathrm{~b}$ illustrates interaction effects between technological change in the energy system, public opinion dynamics and the responsiveness of political institutions. On average, larger endogenous cost reductions lead to larger emissions reduction. However, as this technological feedback must be initiated by climate policy, there is a threshold effect-a large nonlinear change in model behaviour at a particular parameter value-associated with the fraction of the population supporting climate policy. Below a threshold level of support, there is no policy driving the initial deployment required to kickstart the cost-reduction feedback. Moreover, even beyond this threshold, 

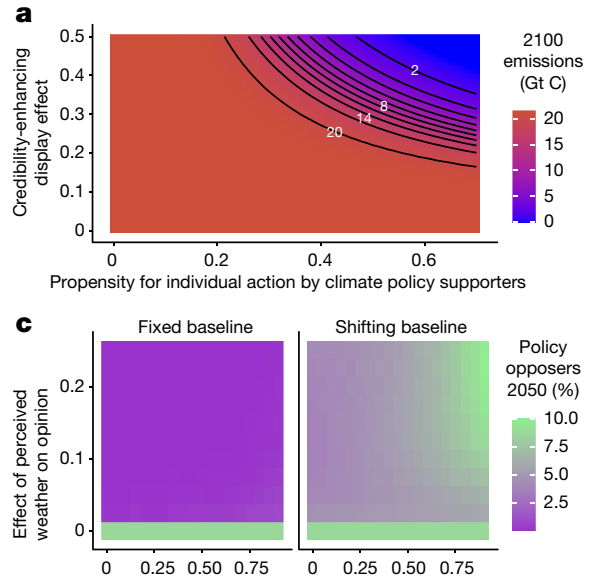

Biased assimilation

Fig. 2 | Tipping points and thresholds in model behaviour. a, Illustration of a tipping point associated with individual adoption of behavioural change by climate policy supporters through the credibility-enhancing display feedback. b. The interactions between endogenous cost reductions in the energy sector and the opinion (fraction of climate policy supporters) and policy (status quo

higher levels of support lead to faster deployment and a larger effect of endogenous cost reductions (indicated by the steepening of the contour lines at the top of the figure). The two panels in Fig. $2 \mathrm{~b}$ highlight how the characteristics of political institutions affect this relationship: those that are less responsive to public opinion (that is, high status quo bias) (Fig. 2b bottom) have a higher threshold for policy support and ramp up climate policy more slowly, leading to higher cumulative emissions over the twenty-first century, even in the presence of a strong cost-reduction feedback in the energy sector.

Perception of climate change. Figure 2 c illustrates how information from the climate system might influence public opinion dynamics if observation of the weather affects support for climate policy (that is, the climate perception feedback). The existence of this feedback can have a decisive influence on opinion dynamics, as illustrated by the threshold behaviour at zero. Model behaviour is substantively different even for very small effects of perceived weather on climate policy opinion compared with model behaviour with no perception effect. However, this is moderated substantially in the presence of cognitive biases that can fully offset the cognition feedback. In model runs using a fixed baseline for the perception of temperature anomalies (Fig. 2c left), the population unanimously favours climate policy, regardless of biased assimilation, because the perceived weather changes are so large.

The presence of shifting baselines (Fig. 2c right) complicates this effect. In particular, when biased assimilation is large, a stronger perception feedback leads to more climate policy opposers in 2050 compared with if that feedback were weaker or absent. This is because, if baselines shift and people compare current weather only to the past 8 years, they will periodically perceive unusually cold anomalies due to natural weather variability, even though temperatures are warm relative to a fixed, preindustrial baseline $\mathrm{e}^{55}$. In the presence of biased assimilation, these perceived cold anomalies reinforce the belief of climate policy opposers in their position, leading to persistence of this opinion group.

\section{Constraining the parameter space}

The illustrations in the previous section highlight how coupled socio-politico-technical feedback processes across components and scales in the climate-social system can produce nonlinear behaviour leading to a wide range of twenty-first century emission trajectories. This complexity characterizes the space of possible climate outcomes when climate policy is modelled as an endogenous product of more

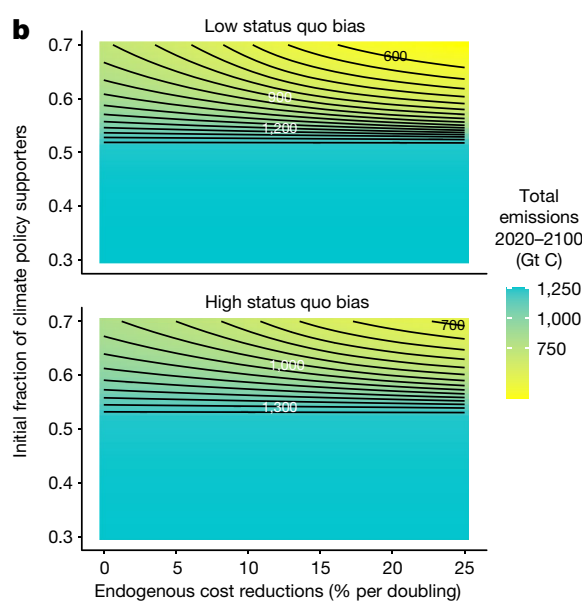

bias) components. c, The effect of the climate perception feedback and specific cognitive biases on public opinion. Model parameters that are not mentioned in each figure panel are kept constant for all of the model runs at the values shown in Extended Data Table1.

fundamental social and political forces. However, identifying outcomes that are more or less likely within this range requires placing some bounds on the model parameters.

The model is a highly aggregated and abstracted representation of the coupled climate-social system, meaning that parameterization is not straightforward. We performed two exercises based on hindcasting performance to partially and probabilistically constrain the parameter space. The first exercise used the population-weighted time series of public opinion on climate change in nine OECD countries (the USA, Canada, France, Germany, Italy, Spain, the UK, Australia and Japan) between 2013 and 2020 from Pew Research Center ${ }^{83}$ and the emissions-weighted average carbon price for the same countries over the same period ${ }^{84}$ tojointly constrain nine parameters in the cognition, opinion and policy components.

The second exercise used recent estimates of the effect of Swedish carbon prices on emissions to constrain two parameters in the emissions component ${ }^{85}$. Although only a tiny fraction of global emissions, the Swedish case is important because Sweden has had the world's highest carbon price for several decades ${ }^{84}$, enabling estimates of the effect of high and sustained carbon prices on emissions. As the model includes a single abatement cost function, this exercise implicitly assumes that the Swedish abatement costs are more widely generalizable, a potential weakness of this calibration point.

For each hindcasting exercise, relevant model components are run in a Monte Carlo mode, sampling independently from the set of possible parameter values. Model output for each run is then compared to the observed time-series and parameter combinations are weighted on the basis of thedistancebetweenmodeloutputandobserveddata(Methods). Differences between the unweighted and weighted parameter distributions provide an indication of the extent to which observations provide constraints on the parameter value.

Extended Data Figures 1 and 2 give the results of these exercises. Extended Data Figure 1a shows how the dynamics of public opinion provide some constraint on both the social conformity and cognition feedback. Public opinion on climate policy over the last decade suggests a population socially sorted within opinion groups (that is, slightly higher network homophily parameter) with relatively slow movement between groups (that is, low persuasive force) and a relatively small role for the individual perception of climate change in opinion formation (low evidence parameter). The exercise is less informative regarding parameters in the policy component, although there is some evidence of status quo bias in the political system. 

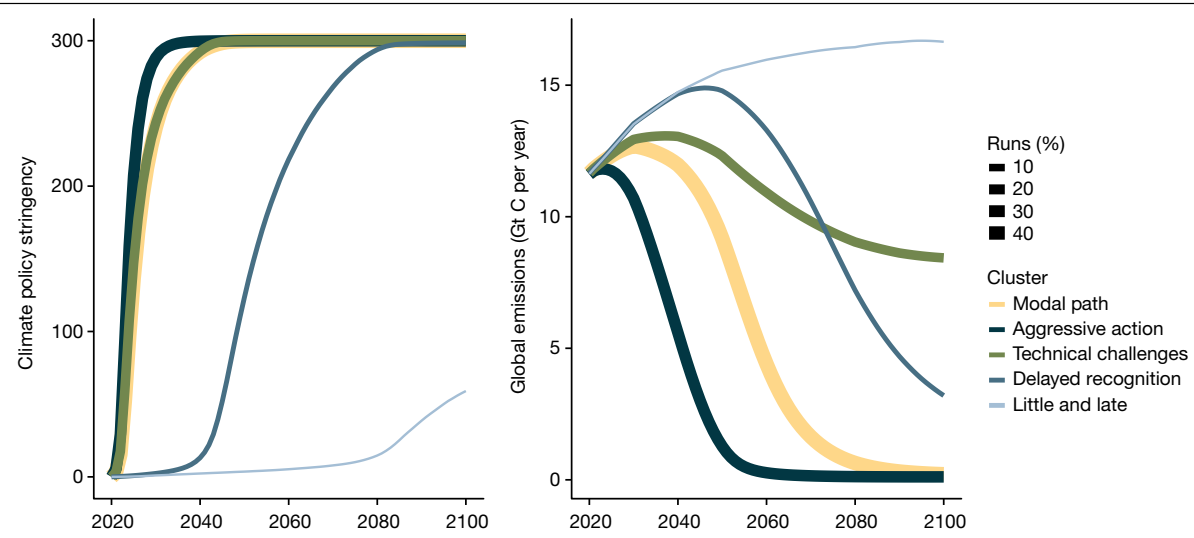

Fig. 3 | Future emissions pathways in the coupled climate-social system. Policy (left) and global $\mathrm{CO}_{2}$ emissions (right) trajectories from $100,000 \mathrm{Monte}$ Carlo runs of the coupled climate-social model, clustered into 5 clusters using $k$-means clustering. The line thickness corresponds to the size of the cluster.

The exercise also constrains the covariance between parameters (Extended Data Fig. 1b). For example, there is covariance between the network homophily, persuasive force and shifting baseline parameters-consistency with observed changes in OECD climate opinion over time requires that opinion groups are socially separated, movement between opinion groups is slow or cognitive biases like shifting baselines limit the role of observed climate change in driving public opinion. Extended Data Figure 2 shows the results of the second hindcasting exercise on the emissions parameters, which suggests a low value for the contemporaneous effect of policy on emissions (maximum mitigation rate), but is uninformative about the persistence of those emissions reductions (maximum mitigation time).

\section{Future emissions pathways}

We used the partially constrained parameter space to probabilistically examine emissions trajectories over the twenty-first century. We performed 100,000 runs of the model, drawing from the joint distribution of the set of hindcast parameters and sampling uniformly over an additional 11 parameters, mostly within the adoption component (with the exception of a triangular distribution for the temperature-emissions feedback based on Woodard et al. ${ }^{8}$ ). The model is initialized using 2020 public opinion ${ }^{83}$ and emissions data and run until 2100 , with parameter values fixed for each model run. We used $k$-means clustering to group together model runs with similar trajectories of climate policy and emissions over the twenty-first century, identifying five distinct pathway types (Methods). A focus on clusters of similar policy and emissions pathways strikes a balance between exploring and explaining the diverse range of model behaviours while avoiding an undue focus on either the central tendency or the extremes of model outcomes.

Figure 3 shows the mean policy and emissions trajectories for the five clusters. The model parameter values characteristic to each cluster indicate the socio-politico-technical states determining each policyemissions trajectory. These parameter values are shown visually in Extended Data Fig. 3. Table 2 describes the different pathways and gives end-of-century warming under the mean emissions scenario in each cluster.

The modal policy-emissions trajectory emerging from the model, $48 \%$ of model runs, has global emissions peaking in the 2030 s and dropping steeply over the 2040-2060 period, resulting in 2100 warming of $2.3^{\circ} \mathrm{C}$ above $1880-1910$ levels. The 2030-2050 emissions pathway displays a perhaps remarkable similarity to recent estimates of the effect of current climate policies or stated nationally determined contributions. Sognnaes et al. ${ }^{11}$ estimate these result in fossil-fuel $\mathrm{CO}_{2}$ emissions between $30-36 \mathrm{GtCO}_{2}$ in 2030 and between $23-40 \mathrm{Gt} \mathrm{CO}_{2}$ in 2050. Assuming that fossil fuels constitute $90 \%$ of total $\mathrm{CO}_{2}$ emissions, equivalent values for the modal path trajectory are $38 \mathrm{Gt} \mathrm{CO}_{2}$ in 2030 and $30 \mathrm{Gt} \mathrm{CO}_{2}$ in 2050 . This congruency arises despite the fact that current and stated climate policies are not input into the model and do not constrain model behaviour.

The second and third most frequent clusters highlight the role of feedback processes discussed above. The 'aggressive action' trajectory is characterized by a strong social-conformity feedback in the opinion component through a high persuasive force parameter, leading to rapid diffusion of support for climate policy that-combined with effective and globally deployed mitigation technologies-drives emissions down faster than in the modal path, limiting warming to below the $2{ }^{\circ} \mathrm{C}$ temperature target. By contrast, the 'technical challenges' trajectory is characterized by a weak or absent learning-by-doing cost reduction feedback within the energy sector, as well as expensive and ineffective mitigation technologies. This pathway has the same climate policy trajectory as the modal path, but the absence of the technical-change feedback driving costs down over time leads to much greater emissions and warming of $3^{\circ} \mathrm{C}$ by 2100 .

Two other trajectories ('delayed recognition' and 'little and late') exhibit multi-decade delays in climate policy, producing higher emissions over the century. These trajectories (which together constitute just over $5 \%$ of model runs), tend to be characterized by weak social conformity feedback in public opinion (through high network homophily and low persuasive force), cognitive biases limiting any effect of perceived climate change in increasing support for climate policy and an unresponsive political system (high status quo bias) that slows climate policy even as public support increases.

Examining the set of parameters that distinguish the clusters of policy and emissions trajectories from each other (Table 1 and Extended Data Fig. 3) reveals an important role for parameters associated with the opinion, mitigation, cognition and policy components, particularly the strength of social conformity (for example, network homophily and persuasive force), the strength of mitigation technology feedback and effectiveness (for example, learning by doing, mitigation rate and lag time), the responsiveness of political institutions (for example, status quo bias) and the role of cognitive biases (for example, shifting baselines and biased assimilation). Parameters from the adoption component notably do not tend to be distinguishing characteristics of policy and emissions pathways. Thus, although the model can exhibit tipping-point behaviour in which individual adoption of behavioural change can be decisive in driving the system towards zero emissions (Fig. 2a), the particular conditions that are necessary for this model behaviour do not appear to be common after constraining the model parameters using the hindcasting exercise.

Drivers of variance in model behaviour were further explored by fitting random-forest models to two outputs of the 100,000 Monte 
Table 2 | Descriptions of distinguishing characteristics, frequency and temperature outcomes

\begin{tabular}{|c|c|c|c|c|}
\hline $\begin{array}{l}\text { Emergent } \\
\text { policy-emissions } \\
\text { trajectory }\end{array}$ & Characteristic parameter sets & Story-line description & $\begin{array}{l}\text { Fraction of } \\
\text { Monte Carlo } \\
\text { runs (\%) }\end{array}$ & $\begin{array}{l}\text { Global } \\
\text { temperature } \\
2091-2100\left({ }^{\circ} \mathrm{C}\right. \\
\text { above } 1880-1910)\end{array}$ \\
\hline Modal path & NA & $\begin{array}{l}\text { As the cluster containing the plurality of model runs, the modal } \\
\text { cluster contains very few distinctive parameter values. It can be } \\
\text { thought of as the baseline model behaviour given the parameter } \\
\text { constraints described in the previous section. Global emissions peak } \\
\text { in the early 2030s and decline to zero by } 2080 \text {. }\end{array}$ & 48.4 & 2.3 \\
\hline Aggressive action & $\begin{array}{l}\text { - High persuasive force } \\
\text { - Low lag time } \\
\text { - High mitigation rates }\end{array}$ & $\begin{array}{l}\text { Rapid diffusion of support for climate policy leads to a rapid increase } \\
\text { in policy ambition over the } 2020 \text { s. Effective emissions-reduction } \\
\text { technologies and rapid diffusion around the world reduce global } \\
\text { emissions to zero by } 2060 \text {. }\end{array}$ & 28.2 & 1.8 \\
\hline Technical challenges & $\begin{array}{l}\text { - Low mitigation rates } \\
\text { - Low mitigation time } \\
\text { - Low learning-by-doing effect }\end{array}$ & $\begin{array}{l}\text { Opinion and policy evolve similarly to the modal path, producing } \\
\text { a carbon price trajectory that ramps up over the } 2020 \text { s and } \\
\text { 2030s. However, technological limitations, including a limited } \\
\text { learning-by-doing feedback, mean this policy produces much } \\
\text { smaller effect on emissions than in the modal path. }\end{array}$ & 18.0 & 3.0 \\
\hline Delayed recognition & $\begin{array}{l}\text { - High shifting baselines } \\
\text { - Low persuasive force } \\
\text { - High status quo bias }\end{array}$ & $\begin{array}{l}\text { Political opinions on climate policy are slow to change and shifting } \\
\text { baselines prevent individual recognition of climate change. Political } \\
\text { systems are slow to respond to public opinion meaning climate } \\
\text { policy gradually ramps up after } 2040 \text {, leading global emissions to } \\
\text { peak around } 2050 .\end{array}$ & 3.6 & 3.1 \\
\hline Little and late & $\begin{array}{l}\text { - High network homophily } \\
\text { - Low persuasive force } \\
\text { - High social norm effect } \\
\text { - High status quo bias } \\
\text { - High biased assimilation } \\
\text { - High shifting baselines }\end{array}$ & $\begin{array}{l}\text { Populations are highly fragmented by policy opinion, preventing the } \\
\text { diffusion of support for climate policy. Biased assimilation combined } \\
\text { with shifting baselines prevents recognition of climate change and } \\
\text { enables opposition to climate policy to persist into the mid-century. } \\
\text { Unresponsive political institutions that are biased towards the status } \\
\text { quo delay climate policy until after } 2080, \text { while a strong effect of } \\
\text { social norms deters individual action to reduce emissions. }\end{array}$ & 1.8 & 3.6 \\
\hline
\end{tabular}

Descriptions of distinguishing characteristics, frequency and temperature outcomes under five clustered policy-emissions trajectories shown in Fig. 3. Temperature change in 2091-2100

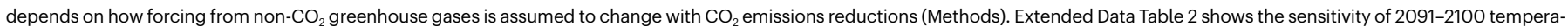
tures to alternate treatment of non- $\mathrm{CO}_{2}$ forcing and the effect of using the MAGICC v.7 climate model ${ }^{94}$.

Carlo runs of the calibrated model: policy in 2030 and cumulative emissions over 2020-2100. Normalized values of the 22 model parameters are used as explanatory variables. Extended Data Figure 4 gives the minimum depth distributions for the most important 10 variables for each model. As with the clustering analysis, variables related to opinion dynamics (persuasive force and network homophily), responsiveness of the political system (status quo bias and political-interest feedback), individual perception of climate change (shifting baselines and evidence effect) and mitigation technologies emerge as important in explaining variation in policy and emissions trajectories over the twenty-first century.

\section{Discussion and conclusions}

The trajectory of global greenhouse gas emissions over the twenty-first century will result from the complex interaction of technologies, governments, markets, individuals and communities. Although a range of disciplines have documented relevant feedback processes, the dynamics of the full system will depend on connections across components and scales. These coupled feedback processes can give rise to complex behaviour with, in some cases, sensitive dependence on parameter values and initial conditions. Even further uncertainties and more complex behaviour could emerge if parameter values were allowed to drift or change over time, for example, due to the evolution or reform of political institutions, a dynamic not explored in this analysis.

However, despite the wide range of plausible behaviour, systematic exploration of the model parameter space combined with observational constraints on parameter values where possible can bound the space of probable outcomes. Despite uncertainties in many parameters, none of the policy-emissions clusters that we identified represent a pure business-as-usual world without climate policy. Even the highest-emission cluster produces warming in 2100 that is lower than the RCP7 business-as-usual baseline of $3.9^{\circ} \mathrm{C}$. The vast majority of runs (98\%) produce warming of more than half a degree lower, although these warming estimates are sensitive to uncertainties in the climate system, including the climate sensitivity and the representation of carbon-cycle feedback, as well as the treatment of non- $\mathrm{CO}_{2}$ greenhouse gases (Methods). Identified emissions trajectories, even the aggressive action scenario, fail to meet the more ambitious Paris Agreement target of limiting warming to $1.5^{\circ} \mathrm{C}$ above pre-industrial levels. This result is not surprising, as all $1.5^{\circ} \mathrm{C}$-consistent emissions scenarios from energy system models include the widespread deployment of negative emissions technology, which is not represented in our model ${ }^{86}$. However, we do estimate a substantial probability of meeting the $2{ }^{\circ} \mathrm{C}$ Paris Agreement target $-28 \%$ of our Monte Carlo runs result in 2091-2100 warming below $2{ }^{\circ} \mathrm{C}$ above $1880-1910$ levels.

We therefore find that socio-politico-technical feedback processes can be decisive for climate policy and emissions outcomes. Yet, they require a distinct and deliberate modelling approach. Exploring emissions pathways as an endogenous outcome of the coupled climatesocial system differs from the typical use of emissions scenarios as exogenous inputs into either energy-economic or general circulation models. This paper seeks to explain alternative emissions and policy trajectories as the product of more fundamental social, political, technical and economic processes. Doing so requires an integrated multidisciplinary perspective-almost all of our identified clusters have distinguishing parameters from more than one model component, implying that the interaction between these subsystems is key in driving variance in potential twenty-first century emissions pathways. Further work to enhance this modelling framework could improve the climate model to better represent non- $\mathrm{CO}_{2}$ forcing and carbon-cycle feedback and would expand the carbon pricing data used for calibration of the policy and mitigation components. 


\section{Online content}

Any methods, additional references, Nature Research reporting summaries, source data, extended data, supplementary information, acknowledgements, peer review information; details of author contributions and competing interests; and statements of data and code availability are available at https://doi.org/10.1038/s41586-022-04423-8.

1. Collins, M. et al. in Climate Change 2013: The Physical Science Basis. Contribution of Working Group 1 to the Fifth Assessment Report of the Intergovernmental Panel on Climate Change (eds Stocker, T. F. et al.) 1029-1136 (Cambridge Univ. Press, 2013).

2. Beckage, B. et al. Linking models of human behaviour and climate alters projected climate change. Nat. Clim. Change 8, 79-84 (2018).

3. Beckage, B. et al. The Earth has humans, so why don't our climate models? Clim. Change 163, 181-188 (2020).

4. Peng, W. et al. Climate policy models need to get real about people-here's how. Nature 594, 174-176 (2021)

5. Geels, F. W., Sovacool, B., Schwanen, T. \& Sorrell, S. Sociotechnical transitions for deep decarbonization. Science 357, 1242-1244 (2017).

6. Farmer, J. D. et al. Sensitive intervention points in the post-carbon transition. Science $\mathbf{3 6 4}$, 132-134 (2019).

7. Otto, I. M. et al. Social tipping dynamics for stabilizing Earth's climate by 2050. Proc. Natl Acad. Sci. USA 117, 2354-2365 (2020)

8. Woodard, D. L., Davis, S. J. \& Randerson, J. T. Economic carbon cycle feedbacks may offset additional warming from natural feedbacks. Proc. Natl Acad. Sci. USA 116, 759-764 (2019).

9. Howard, P. \& Livermore, M. A. Sociopolitical feedbacks and climate change. Harvard Environ. Law Rev. 43, 119-174 (2019).

10. Friedlingstein, P. et al. Global carbon budget 2020. Earth Syst. Sci. Data 12, 3269-3340 (2020).

11. Sognnaes, I. et al. A multi-model analysis of long-term emissions and warming. Nat. Clim. Change 8, 493 (2021)

12. Victor, D. G. et al. Prove Paris was more than paper promises. Nature 548, 25-27 (2017)

13. Field, C. B. \& Mach, K. J. Climate: rightsizing carbon dioxide removal. Science 356 , 706-707 (2017).

14. Tong, D. et al. Committed emissions from existing energy infrastructure jeopardize $1.5^{\circ} \mathrm{C}$ climate target. Nature 572, 373-377 (2019)

15. Smith, S. M. A case for transparent net-zero carbon targets. Commun. Earth Environ. 2, 24 (2021).

16. IPCC. in Special Report on Global Warming of $1.5^{\circ} \mathrm{C}$ (eds Masson-Delmotte, V. et al.) p15 (WMO, 2018).

17. Strauch, Y. Beyond the low-carbon niche: global tipping points in the rise of wind, solar and electric vehicles to regime scale systems. Energy Res. Soc. Sci. 62, 101364 (2020)

18. Fiddaman, T. S. Exploring policy options with a behavioral climate-economy model. Syst. Dyn. Rev. 18, 243-267 (2002).

19. Brauers, H., Oei, P.-Y. \& Walk, P. Comparing coal phase-out pathways: the United Kingdom's and Germany's diverging transitions. Environ. Innov. Soc. Transitions 37, 238-253 (2020).

20. Sperling, D. Electric vehicles: approaching the tipping point. Bull. At. Sci. 74, 11-18 (2018).

21. Hoekstra, A., Steinbuch, M. \& Verbong, G. Creating agent-based energy transition management models that can uncover profitable pathways to climate change mitigation. Complexity 2017, 1967645 (2017)

22. Vinichenko, V., Cherp, A. \& Jewell, J. Historical precedents and feasibility of rapid coal and gas decline required for the $1.5^{\circ} \mathrm{C}$ target. One Earth 4, 1477-1490 (2021).

23. Fouquet, R. Historical energy transitions: speed, prices and system transformation. Energy Res. Soc. Sci. 22, 7-12 (2016).

24. Centola, D., Becker, J., Brackbill, D. \& Baronchelli, A. Experimental evidence for tipping points in social convention. Science 360, 1116-1119 (2018)

25. Hacker, J. S. \& Pierson, P. Policy feedback in an age of polarization. Ann. Am. Acad. Pol. Soc. Sci. 685, 8-28 (2019)

26. Pierson, P. When effect becomes cause: policy feedback and political change. World Polit. 45, 595-628 (1993).

27. Stokes, L. C. Short Circuiting Policy: Interest Groups and the Battle Over Clearn Energy and Climate Policy in the American States (Oxford Univ. Press, 2020).

28. Berglund, C. \& Söderholm, P. Modeling technical change in energy system analysis: analyzing the introduction of learning-by-doing in bottom-up energy models. Energy Policy 34, 1344-1356 (2006).

29. EN-ROADS, https://en-roads.climateinteractive.org/scenario.html (Climate Interactive accessed 16 November 2021).

30. Latané, B. The psychology of social impact. Am. Psychol. 36, 343-356 (1981)

31. Mason, W. A., Conrey, F. R. \& Smith, E. R. Situating social influence processes: dynamic, multidirectional flows of influence within social networks. Personal. Soc. Psychol. Rev. 11 279-300 (2007)

32. Bénabou, R. \& Tirole, J. Incentives and prosocial behavior. Am. Econ. Rev. 96, 1652-1678 (2006)

33. McDonald, R. I. \& Crandall, C. S. Social norms and social influence. Curr. Opin. Behav. Sci. 3, 147-151 (2015).

34. Goldberg, M. H., van der Linden, S., Leiserowitz, A. \& Maibach, E. Perceived social consensus can reduce ideological biases on climate change. Environ. Behav. 52, 495-517 (2020)

35. Bamberg, S. \& Moser, G. Twenty years after Hines, Hungerford and Tomera: a new meta-analysis of psycho-social determinants of pro-environmental behavior. J. Environ. Psychol. 27, 14-25 (2007)
36. Schultz, P. W., Nolan, J. M. \& Cialdini, R. B. The constructive, destructive, and reconstructive power of social norms. Psychol. Sci. 10, 429-434 (2007).

37. Bollinger, B. \& Gillingham, K. Peer-effects in the diffusion of solar photovoltaics. Mark. Sci. 31, 900-912 (2012)

38. Andreoni, J., Nikiforakis, N. \& Siegenthaler, S. Predicting social tipping and norm change in controlled experiments. Proc. Natl Acad. Sci. USA 118, e2014893118 (2021).

39. Santer, B. D. et al. Identifying human influences on atmospheric temperature. Proc. Natl Acad. Sci. USA 110, 26-33 (2013).

40. Marvel, K. \& Bonfils, C. Identifying external influences on global precipitation. Proc. Nat Acad. Sci. USA 110, 19301-19306 (2013).

41. Parmesan, C. \& Yohe, G. A globally coherent fingerprint of climate change impacts across natural systems. Nature 421, 37-42 (2003).

42. Diffenbaugh, N. S. et al. Quantifying the influence of global warming on unprecedented extreme climate events. Proc. Natl Acad. Sci. USA 114, 4881-4886 (2017).

43. Ricke K. L. \& Caldeira K. Natural climate variability and future climate policy. Nat. Clim Chang. 4, 333-338 (2014)

44. Howe, P. D., Markowitz, E. M., Lee, T. M., Ko, C.-Y. \& Leiserowitz, A. Global perceptions of local temperature change. Nat. Clim. Change 3, 352-356 (2012).

45. Howe, P. D. \& Leiserowitz, A. Who remembers a hot summer or a cold winter? The asymmetric effect of beliefs about global warming on perceptions of local climate conditions in the U.S. Glob. Environ. Change 23, 1488-1500 (2013).

46. Deryugina, T. How do people update? The effects of local weather fluctuations on beliefs about global warming. Clim. Change 118, 397-416 (2013).

47. Kaufmann, R. K. et al. Spatial heterogeneity of climate change as an experiential basis for skepticism. Proc. Natl Acad. Sci. USA 114, 67-71 (2017).

48. Hamilton, L. C. \& Stampone, M. D. Blowin' in the wind: short-term weather and belief in anthropogenic climate change. Weather Clim. Soc. 5, 112-119 (2013).

49. Zaval, L., Keenan, E. A., Johnson, E. J. \& Weber, E. U. How warm days increase belief in global warming. Nat. Clim. Change 4, 143-147 (2014).

50. Howe, P. D., Marlon, J. R., Mildenberger, M. \& Shield, B. S. How will climate change shape climate opinion? Environ. Res. Lett. 14, 113001 (2019).

51. McCright, A. M., Dunlap, R. E. \& Xiao, C. The impacts of temperature anomalies and political orientation on perceived winter warming. Nat. Clim. Change 4, 1077-1081 (2014).

52. Hazlett, C. \& Mildenberger, M. Wildfire exposure increases pro-environment voting within Democratic but not Republican areas. Am. Polit. Sci. Rev. 114, 1359-1365 (2020).

53. Druckman, J. N. \& McGrath, M. C. The evidence for motivated reasoning in climate change preference formation. Nat. Clim. Change 9, 111-119 (2019).

54. Kahan, D. M., Jenkins-Smith, H. \& Braman, D. Cultural cognition of scientific consensus. J. Risk Res. 14, 147-174 (2011)

55. Moore, F. C., Obradovich, N., Lehner, F. \& Baylis, P. Rapidly declining remarkability of temperature anomalies may obscure public perception of climate change. Proc. Natl Acad. Sci. USA 116, 4905-4910 (2019).

56. Mildenberger, M. Carbon Captured: How Business and Labor Control Climate Politics (MIT Press, 2020).

57. Hertel-Fernandez, A., Mildenberger, M. \& Stokes, L. C. Legislative staff and representation in Congress. Am. Polit. Sci. Rev. 113, 1-18 (2018).

58. Jenkins, J. D. Political economy constraints on carbon pricing policies: what are the implications for economic efficiency, environmental efficacy, and climate policy design? Energy Policy 69, 467-477 (2014)

59. Truelove, H. B., Carrico, A. R., Weber, E. U., Raimi, K. T. \& Vandenbergh, M. P. Positive and negative spillover of pro-environmental behavior: an integrative review and theoretical framework. Glob. Environ. Change 29, 127-138 (2014).

60. Sparkman, G. \& Walton, G. M. Dynamic norms promote sustainable behavior, even if it is counternormative. Psychol. Sci. 28, 1663-1674 (2017).

61. Kraft-Todd, G. T., Bollinger, B., Gillingham, K., Lamp, S. \& Rand, D. G. Credibility-enhancing displays promote the provision of non-normative public goods. Nature 563, 245-248 (2018).

62. Attari, S. Z., Krantz, D. H. \& Weber, E. U. Statements about climate researchers' carbon footprints affect their credibility and the impact of their advice. Clim. Change 138 325-338 (2016)

63. Attari, S. Z., Krantz, D. H. \& Weber, E. U. Climate change communicators' carbon footprints affect their audience's policy support. Clim. Change 154, 529-545 (2019)

64. Tankard, M. E. \& Paluck, E. L. Norm perception as a vehicle for social change. Soc. Issues Policy Rev. 10, 181-211 (2016)

65. Kahan, D. M. What do alternative sanctions mean? Univ. Chicago Law Rev. 63, 591-653 (1996).

66. Sunstein, C. R. On the expressive function of law. Univ. PA Law Rev. 281, 2021-2054 (1996).

67. McAdams, R. H. An attitudinal theory of expressive law. Oregon Law Rev. 79, 339-390 (2000)

68. Posner, E. A. Symbols, signals, and social norms in politics and the law. J. Legal Stud. 27 765-797 (1998).

69. Ofosu, E. K., Chambers, M. K., Chen, J. M. \& Hehman, E. Same-sex marriage legalization associated with reduced implicit and explicit antigay bias. Proc. Natl Acad. Sci. USA 116 8846-8851 (2019).

70. Tankard, M. E. \& Paluck, E. L. The effect of a supreme court decision regarding gay marriage on social norms and personal attitudes. Psychol. Sci. 28, 1334-1344 (2017).

71. Orbell, S. et al. Social-cognitive beliefs, alcohol, and tobacco use: a prospective community study of change following a ban on smoking in public places. Health Psychol. 28, 753-761 (2009).

72. Galbiati, R., Henry, E., Jacquemet, N. \& Lobeck, M. How laws affect the perception of norms: empirical evidence from the lockdown. PLOS ONE 16, e0256624 (2021).

73. Trancik, J. E. Scale and innovation in the energy sector: a focus on photovoltaics and nuclear fission. Environ. Res. Lett. 1, 014009 (2006)

74. Yeh, S. \& Rubin, E. S. A review of uncertainties in technology experience curves. Energy Econ. 34, 762-771 (2012). 
75. Rubin, E. S., Azevedo, I. M. L., Jaramillo, P. \& Yeh, S. A review of learning rates for electricity supply technologies. Energy Policy 86, 198-218 (2015).

76. Dell, M., Jones, B. F. \& Olken, B. A. Temperature shocks and economic growth: evidence from the last half century. Am. Econ. J. Macroecon. 4, 66-95 (2012)

77. Burke, M., Hsiang, S. M. \& Miguel, E. Global non-linear effect of temperature on economic production. Nature 527, 235-239 (2015).

78. Rode, A. et al. Estimating a social cost of carbon for global energy consumption. Nature 598, 308-314 (2021)

79. Hardin, E. et al. California drought increases $\mathrm{CO}_{2}$ footprint of energy. Sustain. Cities Soc. 28, 450-452 (2017)

80. Mideksa, T. K. \& Kallbekken, S. The impact of climate change on the electricity market: a review. Energy Policy 38, 3579-3585 (2010).

81. Le Quéré, C. et al. Temporary reduction in daily global $\mathrm{CO}_{2}$ emissions during the COVID-19 forced confinement. Nat. Clim. Change 10, 647-653 (2020).

82. Liu, Z. et al. Near-real-time monitoring of global $\mathrm{CO}_{2}$ emissions reveals the effects of the COVID-19 pandemic. Nat. Commun. 11, 5172 (2020).

83. Fagan, M. \& Huang, C. Many Globally are as Concerned About Climate Change as About the Spread of Infections Diseases, https://www.pewresearch.org/fact-tank/2020/10/16/ many-globally-are-as-concerned-about-climate-change-as-about-the-spread-ofinfectious-diseases/ (Pew Research Center, 2020).

84. World Bank. Carbon Pricing Dashboard https://carbonpricingdashboard.worldbank.org/ World Bank, 2021).

85. Andersson, J. J. Carbon taxes and $\mathrm{CO}_{2}$ emissions: Sweden as a case study. Am. Econ. J. Econ. Policy 11, 1-30 (2019).
86. Hilaire, J. et al. Negative emissions and international climate goals-learning from and about mitigation scenarios. Clim. Change 157, 189-219 (2019).

87. Leiserowitz, A. A. et al. Politics \& Global Warming, March 2018 (Yale Univ. \& George Mason Univ., 2018).

88. Jurkowitz, M., Mitchell, A. Shearer, E. \& Walker, M. U.S. Media Polarization and the 2020 Election: A Nation Divided (Pew Research Center, 2020).

89. Lang, C. \& Pearson-Merkowitz, S. Partisan sorting in the United States, 1972-2012: new evidence from a dynamic analysis. Polit. Geogr. 48, 119-129 (2015).

90. Fernandez, B. R. \& Rodrik, D. Resistance to reform: status quo bias in the presence of individual-specific uncertainty. Am. Econ. Rev. 81, 1146-1155 (1991).

91. Hausfather, Z. \& Peters, G. P. Emissions-the 'business as usual' story is misleading. Nature 577, 618-620 (2020).

92. Nordhaus, W. D. A Question of Balance: Weighing the Options on Global Warming Policy (Yale Univ. Press, 2008).

93. Cai, Y. \& Lontzek, T. S. The social cost of carbon with economic and climate risks. J. Polit. Econ. 127, 2684-2734 (2019).

94. Meinshausen, M. et al. The shared socio-economic pathway (SSP) greenhouse gas concentrations and their extensions to 2500. Geosci. Model Dev. 13, 3571-3605 (2020).

Publisher's note Springer Nature remains neutral with regard to jurisdictional claims in published maps and institutional affiliations.

(c) The Author(s), under exclusive licence to Springer Nature Limited 2022 


\section{Methods}

Model components and the feedback processes between and within components were identified from a review of literature across relevant fields including social and cognitive psychology, economics, sociology, law, political science and energy systems engineering $8,24,26,27,31-78$. The climate-social model was developed using relationships and feedback processes identified from this review (illustrated in Fig. 1, described in Table 1 and documented in the 'Model documentation' section of the Supplementary Information). Specific parameterizations or functional forms were derived from the literature where available. These are (1) parameterization of the temperature-emissions feedback using Woodard et al. ${ }^{8}$; (2) parameterization of the shifting-baseline effect using Moore et al..$^{55}$; (3) parameterization of the learning-by-doing effect using Rubin et al. ${ }^{75}$; and (4) use of a logistic uptake curve to represent uptake of individual behaviour change as commonly used in the technology adoption literature ${ }^{95}$. However, in many cases, only qualitative descriptions or relationships were described in the literature. In these cases (normative force of law feedback, political interest feedback, social norm effect, social homophily, status quo bias, credibility-enhancing display feedback and biased assimilation), we attempted to translate the relationships into appropriate functional forms, described in more detail in the 'Extended model documentation' section of the Supplementary Information.

The behaviour of the model, particularly the potential for crosscomponent feedback processes and tipping points was investigated using systematic sweeps of the parameters shown in Fig. 2, keeping all of the other model parameters fixed. Other model parameters for this part of the analysis were deliberately chosen to demonstrate the existence of tipping or threshold behaviour following an informal, qualitative exploration of the parameter space and are given in Extended Data Table 1. The parameters that were varied in this analysis were chosen to exemplify thresholds and tipping-point behaviour as well as the interactions that moderate those effects.

Two hindcasting exercises were conducted to partially constrain some key model parameters (given in Extended Data Figs. 1 and 2) using historical data. The first used time series of public opinion on climate change and carbon prices from 2013 to 2020 for nine OECD countries (the USA, Canada, Japan, Australia, the UK, Germany, France, Italy and Spain) to jointly constrain nine parameters in the opinion, policy and cognition components. Opinion data came from the Pew Research Center ${ }^{83}$, which asked respondents whether they thought global climate change was a major threat, a minor threat or not a threat. These three categories were mapped onto those supporting, neutral or opposed to climate policy and data from nine countries were aggregated into a single population-weighted time series ${ }^{96}$. Carbon price data come from the World Bank Carbon Pricing Dashboard and we calculate a single, emissions-weighted carbon price for the nine OECD countries between 2013 and 2020 (ref. ${ }^{84}$ ). This constrains the calibration to only explicit carbon prices based on taxes or emissions trading schemes, ignoring implicit carbon prices arising through other forms of climate and energy regulation, for which data are not readily available.

The model was initialized using carbon prices and opinion distribution from 2013 and then run 20,000 times, sampling from the distributions over nine model parameters (given in Extended Data Fig. 1). We use uniform prior distributions over the parameters, except in a couple of cases for which parameters are structurally related to each other (specifically the 'weak persuasive force' is constrained to be smaller than the 'strong persuasive force' and the 'political interest feedback' is constrained to be smaller than the 'status quo bias') or where some prior evidence suggests non-uniform distributions. Specifically, we used informative prior distributions for the network homophily parameter, placing higher weight on larger values (that is, more social separation between opinion groups ${ }^{97,98}$ ) and for the shifting baselines parameter, placing more weight on the existence of shifting baselines ${ }^{55}$. For each model run, we defined a probability weight associated with the parameters based on its error in predicting 2014-2020 opinion and policy (that is, carbon prices) relative to the set of all 20,000 runs (details are provided in the 'Weighting scheme for hindcast parameter constraints' section of the Supplementary Information). Initial distributions and weighted distributions based on hindcasting performance are given in Extended Data Fig. 1a.

A second tuning exercise was performed for two parameters in the emissions component (maximum mitigation rate and maximum mitigation time) using evidence from Andersson ${ }^{85}$ on the effect of the Swedish carbon price over the period 1991-2005. Andersson estimates that carbon pricing reduced emissions by $12.5 \%$ in 2005 . The emissions component was forced with observed Swedish carbon prices over this time period and run 10,000 times, sampling from independent uniform distributions over the two mitigation parameters. A weighting scheme based on the difference in the modelled mitigation rate in 2005 and the estimated effect of the policy in Andersson ${ }^{85}$ was applied to the initial uniform distributions, shown in Extended Data Fig. 2. As with the first calibration exercise, this again relies on only explicit carbon tax levels, ignoring the effects of fuel taxes or the shadow costs of other climate or energy regulation.

To evaluate the effectiveness of the parameter-tuning process for parameters in the opinion, policy and cognition components, we also performed a leave-one-out cross-validation of the model. Component parameters were tuned after dropping data from each year between 2014 and 2020 in sequence. The trained model was then run 20,000 times in Monte Carlo mode to predict the missing year value. We find that the average out-of-sample root mean squared error is US $\$ 2.5$ for the carbon price and 5.4 percentage points for the combined neutral and opposed opinion groups.

Finally, a full Monte Carlo analysis of the model was performed. Parameters partly constrained in the hindcasting exercises were drawn from the weighted distributions shown in Extended Data Figs. 1 and 2. An additional 11 parameters (primarily in the adoption component, and listed in the 'Monte Carlo parameter sampling details' section of the Supplementary Information) were drawn from independent uniform distributions (with the exception of a triangular distribution for the temperature-emissions feedback based on Woodard et al. ${ }^{8}$ ). The model was run 100,000 times, initialized using opinion distribution in 2020 and running until 2100.

Clusters of similar policy and emissions trajectories were identified by concatenating the two time series for each model run, scaling each column and applying $k$-means clustering to the resulting data frame. We decided on 5 clusters based on reductions in the within-cluster variance for 2-9 clusters (Extended Data Fig. 5). Characteristic parameter values for each cluster (Extended Data Fig. 3) were identified by first scaling the parameter values across all runs and then plotting average values for each cluster. Values close to zero mean that the model runs within the cluster have parameter values close to the ensemble average, whereas high or low values suggest sorting of those ensemble runs into the cluster and that these values are therefore important in producing the policy-emissions trajectory associated with that cluster.

The temperature outcomes for emissions pathways reported in Table 2 depend on how forcing from non- $\mathrm{CO}_{2}$ greenhouse gases are assumed to change with $\mathrm{CO}_{2}$ emissions. Following the 2016 DICE model ${ }^{99}$, non- $\mathrm{CO}_{2}$ forcings appear in the model as an 'exogenous forcing' term applied on top of radiative forcing from $\mathrm{CO}_{2}$. We allow this forcing to vary with $\mathrm{CO}_{2}$ emissions based on a fitted relationship between reductions in $\mathrm{CO}_{2}$ and reductions in $\mathrm{CH}_{4}$ and $\mathrm{N}_{2} \mathrm{O}$ observed in the SSP-RCP emissions database ${ }^{100}$, which suggests that these gases are reduced at approximately half the rate of $\mathrm{CO}_{2}$ (Extended Data Fig. 6). The sensitivity of 2091-2100 temperature estimates to this modelling choice is shown in Extended Data Table 2.

Moreover, the DICE climate model used in the coupled climatesocial model and to estimate warming in Table 2 has a slow temperature 
response and lacks representation of carbon-cycle feedback ${ }^{101}$. Thus, in Extended Data Table 2, we also show 2091-2100 warming under the five emissions trajectories using the MAGICC v.7 climate model, which includes saturation of the land and ocean carbon sinks, a more complete treatment of non- $\mathrm{CO}_{2}$ forcing and is calibrated to reproduce behaviour of much larger general circulation models ${ }^{94,102}$. End-of-century warming on the basis of the DICE model is well within the uncertainty range based on 100 Monte Carlo runs of MAGICC. The largest difference with median MAGICC warming is $0.2^{\circ} \mathrm{C}$ for the aggressive action pathway. All of the other scenarios are within $0.1^{\circ} \mathrm{C}$ of the median.

The coupled climate-social model is coded in R (v.3.6.3). Model output and behaviour were also analysed using the tidyverse, randomForest and randomForestExplainer packages. Figure 3 and Extended Data Figs. 3, 4 and 6 were made using the ggplot 2 package.

\section{Reporting summary}

Further information on research design is available in the Nature Research Reporting Summary linked to this paper.

\section{Data availability}

All data used in the Article are publicly available online (https://doi. org/10.24433/CO.5602083.v1). Source data are provided with this paper.

\section{Code availability}

Model code and code to reproduce the analysis in this Article are provided in an online repository (https://doi.org/10.24433/CO.5602083.v1).

95. Rogers, E. M. Diffusion of Innovations (Free Press, 2003).

96. UN Population Division. World Population Prospects 2019, https://population.un.org/wpp/ Download/Standard/Population/ (UN, 2019).
97. Halberstam, Y. \& Knight, B. Homophily, group size, and the diffusion of political information in social networks: evidence from Twitter. J. Public Econ. 143, 73-88 (2016).

98. Huber, G. A. \& Malhotra, N. Political homophily in social relationships: evidence from online dating behavior. J. Polit. 79, 269-283 (2017)

99. Nordhaus, W. D. Revisiting the social cost of carbon. Proc. Natl Acad. Sci. USA 114, 1518-1523 (2017).

100. SSP Public Database-Version 2.0, https://tntcat.iiasa.ac.at/SspDb, accessed 24 November 2021 (IIASA, 2018).

101. Dietz, S., van der Ploeg, F., Rezai, A. \& Venmans, F. Are economists getting climate dynamics right and does it matter? J. Assoc. Environ. Resour. Econ. 8, 895-921 (2021)

102. Meinshausen, M., Raper, S. C. B. \& Wigley, T. M. L. Emulating coupled atmosphere-ocean and carbon cycle models with a simpler model, MAGICC6-part 1: model description and calibration. Atmos. Chem. Phys. 11, 1417-1456 (2011).

103. Meinshausen, M. et al. The RCP greenhouse gas concentrations and their extensions from 1765 to 2300. Clim. Change 109, 213-241 (2011).

104. MAGICC, https://live.magicc.org (Climate Resource, accessed 10 December 2021).

Acknowledgements We thank S. Metcalf, D. Rothman, T. Franck and A. Kinzig for discussions and comments on this work. This work resulted from a working group supported by the National Socio-Environmental Synthesis Center (SESYNC) under funding received from the National Science Foundation (NSF) DBI-1052875. F.C.M. acknowledges the support of NSF (award no. 1924378). K.L. acknowledges the support of the NSF under EPSCoR Cooperative Agreement OIA-1655221. L.J.G. acknowledges the support of NSF (award no. 1300426 to the National Institute for Mathematical and Biological Synthesis). B.B. acknowledges the support of the National Science Foundation through VT EPSCoR (award no. 1556770).

Author contributions All of the authors contributed to the conceptual design of the model. F.C.M., K.L., K.J.M. and Y.A.S. performed the literature review of evidence for feedback processes. F.C.M. coded the model, analysed results and generated the figures. All of the authors contributed to writing the manuscript.

Competing interests The authors declare no competing interests.

Additional information

Supplementary information The online version contains supplementary material available at https://doi.org/10.1038/s41586-022-04423-8.

Correspondence and requests for materials should be addressed to Frances $\mathrm{C}$. Moore Peer review information Nature thanks Gernot Wagner and the other, anonymous, reviewer(s) for their contribution to the peer review of this work. Peer reviewer reports are available. Reprints and permissions information is available at http://www.nature.com/reprints. 


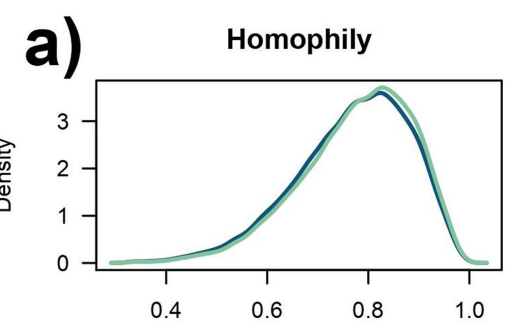

Evidence

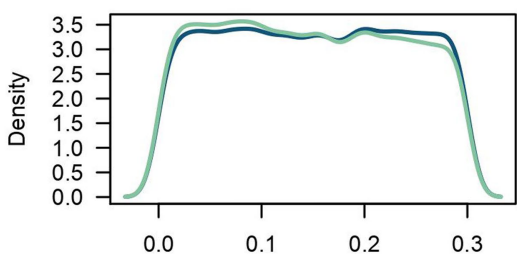

Pol Int Feedback

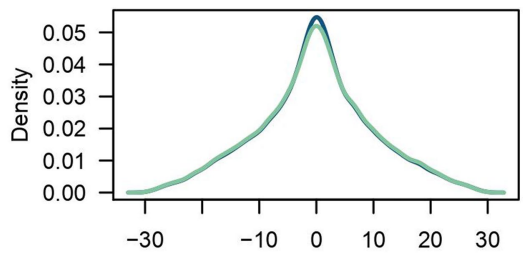

Strong Force

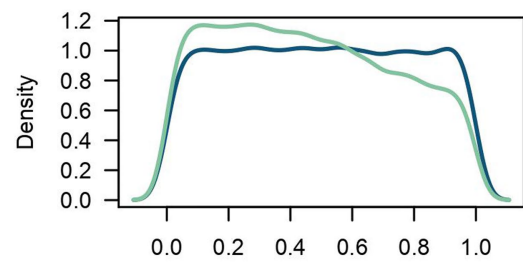

Pol-Opinion

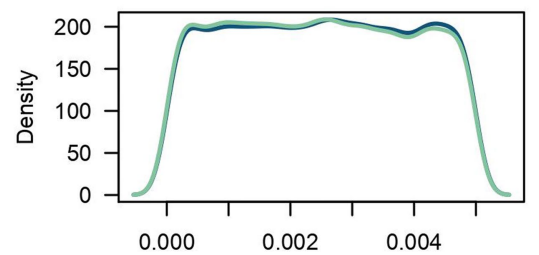

Biased Assimilation

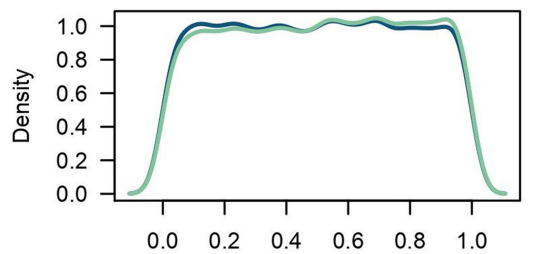

Weak Force

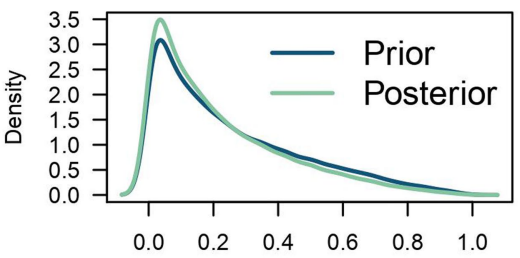

Status-Quo Bias

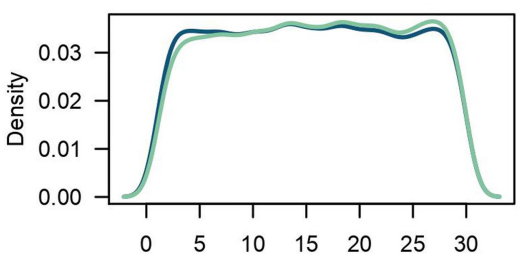

Shifting Baselines

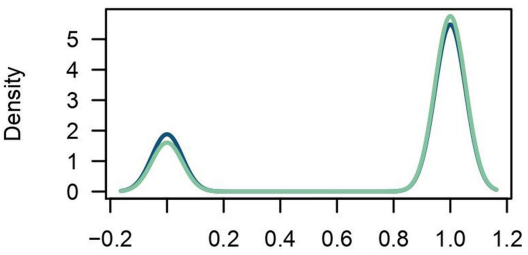

b)
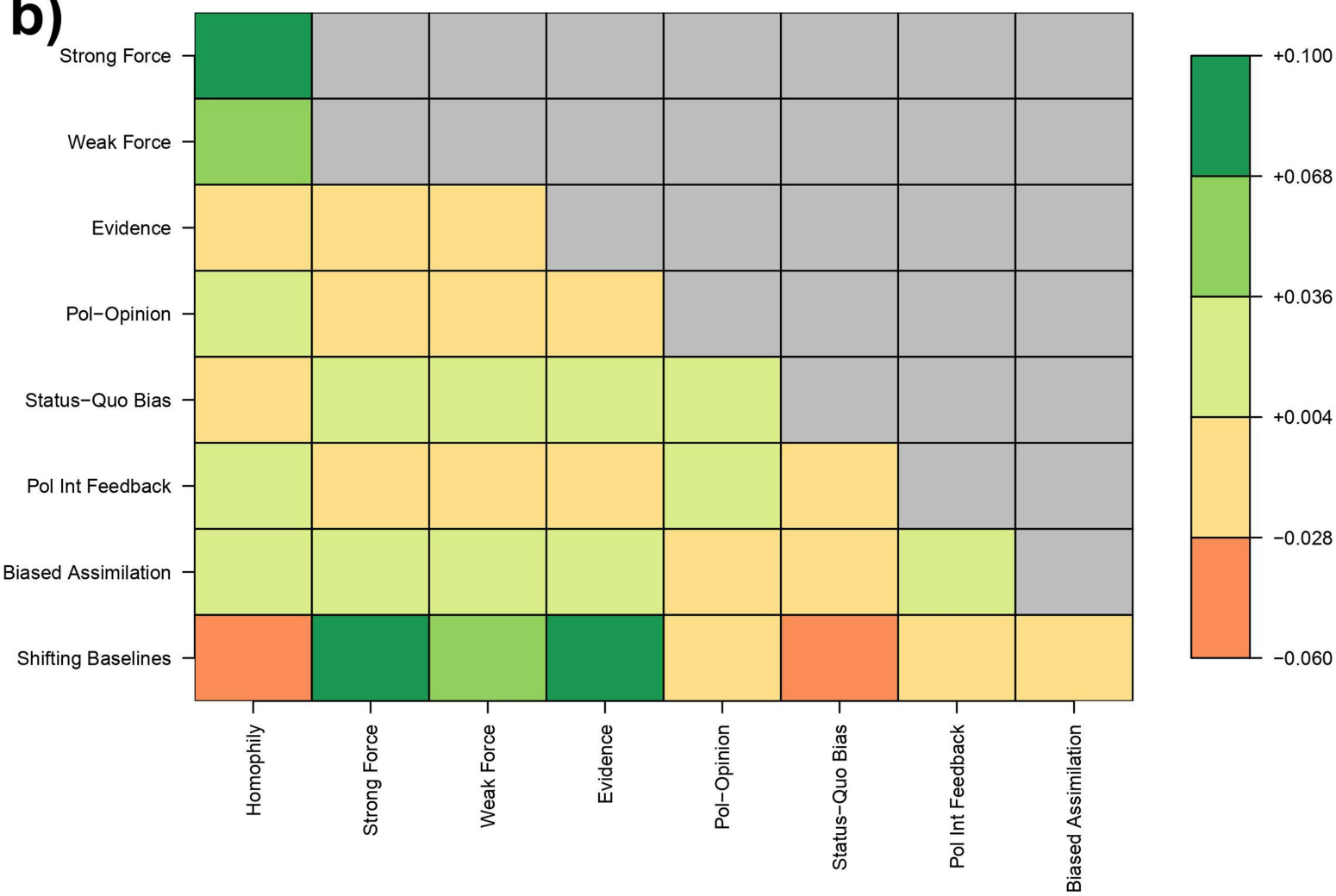

Extended Data Fig. 1 | Results of the first hindcasting exercise to constrain parameters in the opinion, policy, and cognition components. a) Parameter distributions before (prior) and after (posterior) weighting based on fit with observed public opinion and policy trajectories over 2013-2020 for nine OECD nations (US, Canada, Japan, Australia, UK, Germany, France. Spain and Italy). b) Covariance of parameters after weighting based on model performance. Covariance of the unweighted parameters is zero as they are drawn independently, meaning covariance of the weighted distribution is induced by model performance of particular parameter combinations. 
Max Annual Mitigation

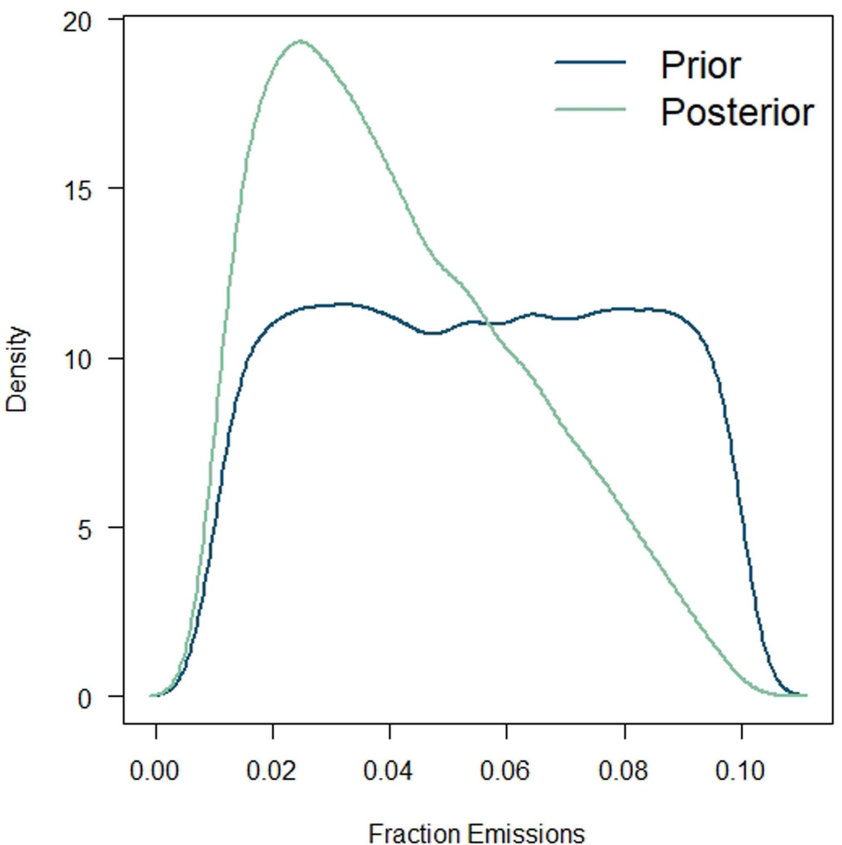

Max Mitigation Scaling

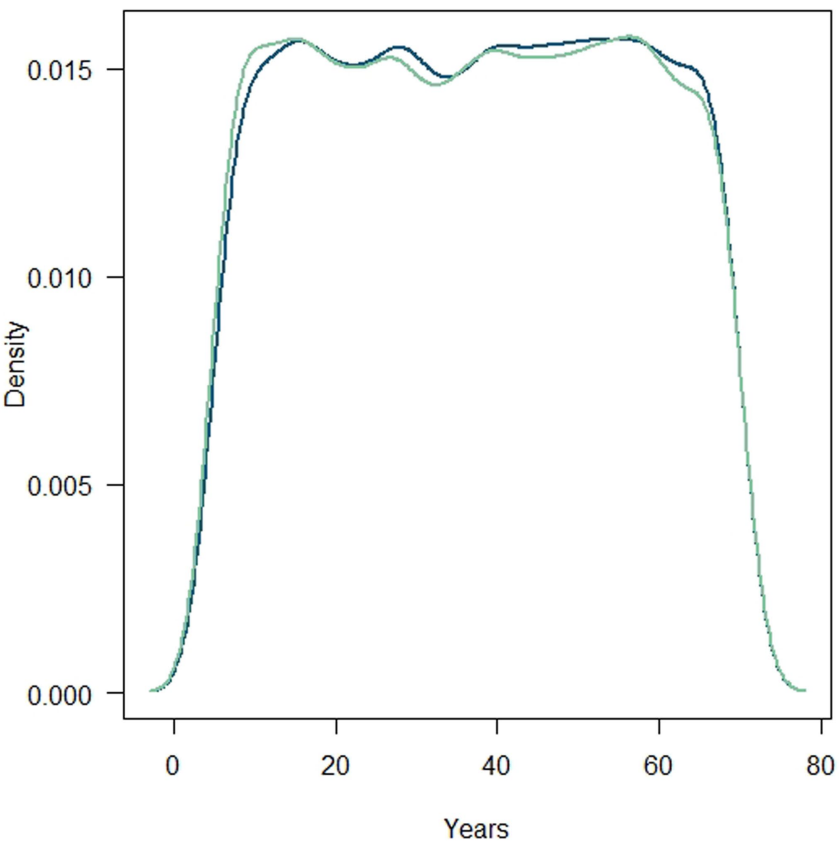

Extended Data Fig. $2 \mid$ Results of the second hindcasting exercise to constrain parameters in the mitigation component. Parameter distributions before (prior) and after (posterior) weighting based on distance from observed response of Swedish emissions to carbon pricing based on Andersson ${ }^{85}$. 


\section{Article}

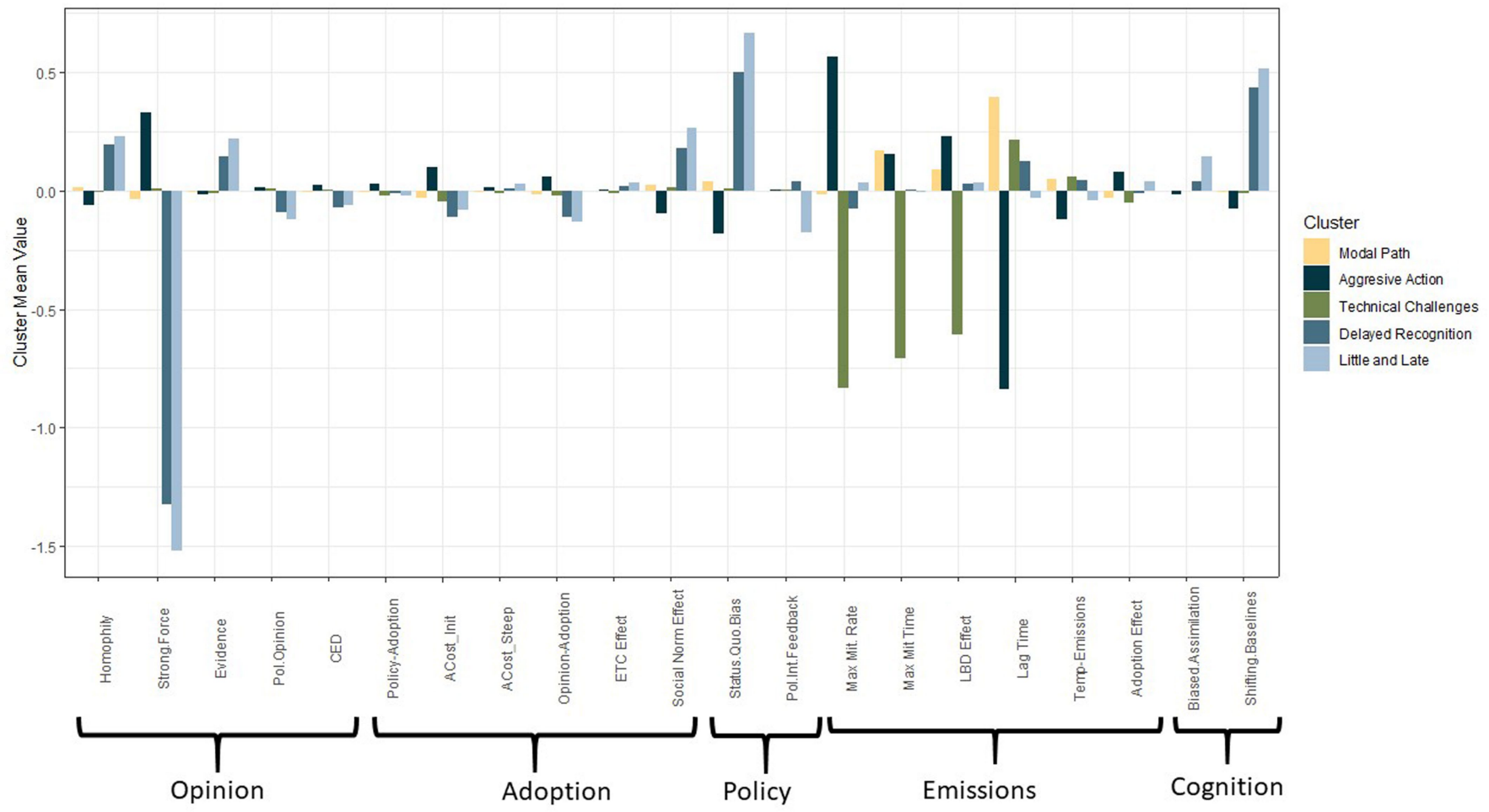

Extended Data Fig. 3 | Characteristic parameter combinations for the policy-emissions trajectory clusters. Average parameter values by policy-emissions trajectory cluster for the 100,000 Monte Carlo model runs, after normalizing by subtracting the mean and dividing by the standard

deviation of parameter values across all samples. High or low values imply that those parameters values are important in producing the trajectories in that particular cluster. 


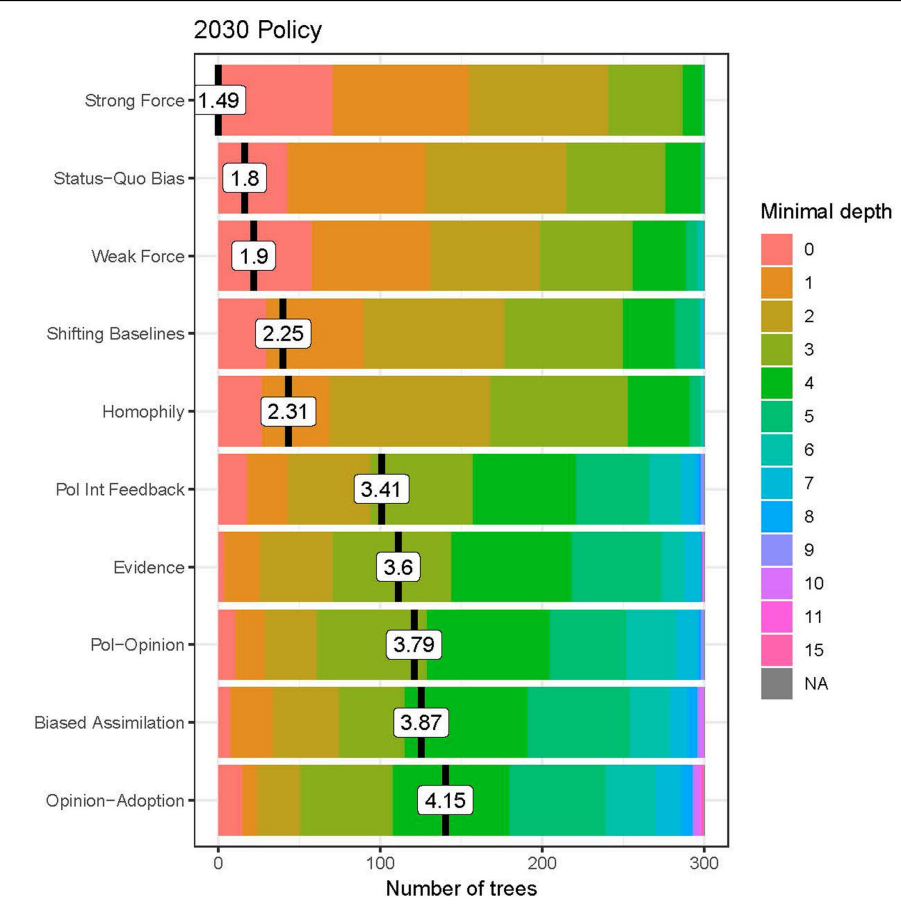

Extended Data Fig. 4 | Minimum depth distributions for random forest models. Minimum depth distributions (level at which a variable first appears in the regression tree) for two random forest models of the 100,000 Monte Carlo runs, for the 2030 carbon price (left) and cumulative emissions 2020-2100

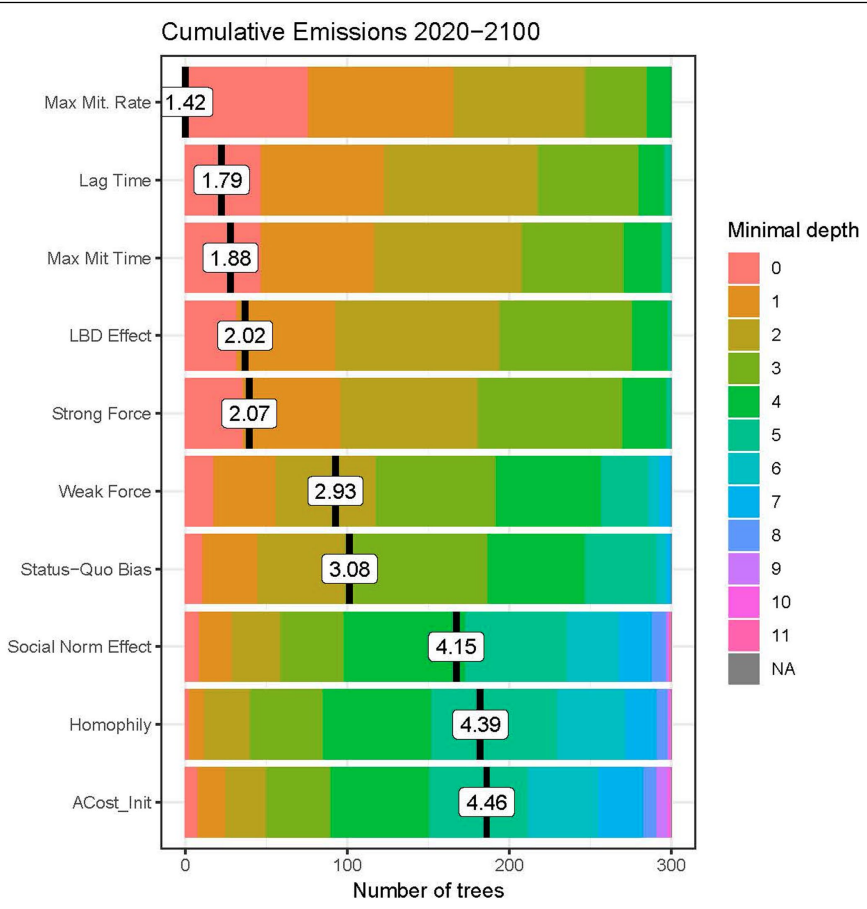

(right). Both random forest models include standardized values of all 22 model parameters varied in the Monte Carlo analysis. Figures show the 10 variables with lowest average minimum depth. 


\section{Article}

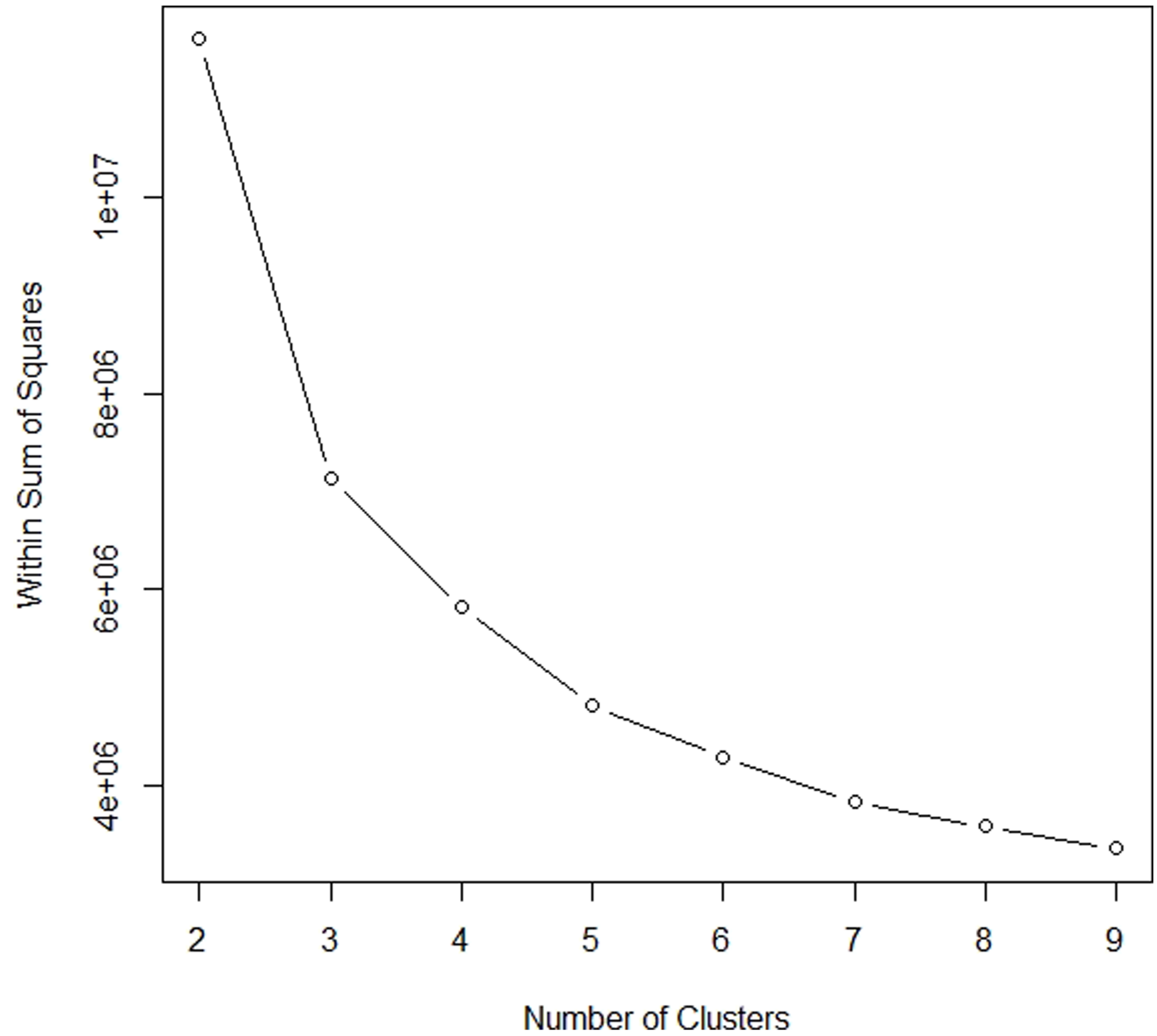

Extended Data Fig. 5 | Total within-cluster sum of squares for 2-9 clusters. Five clusters were chosen based on the reduction in slope for larger number of clusters. 


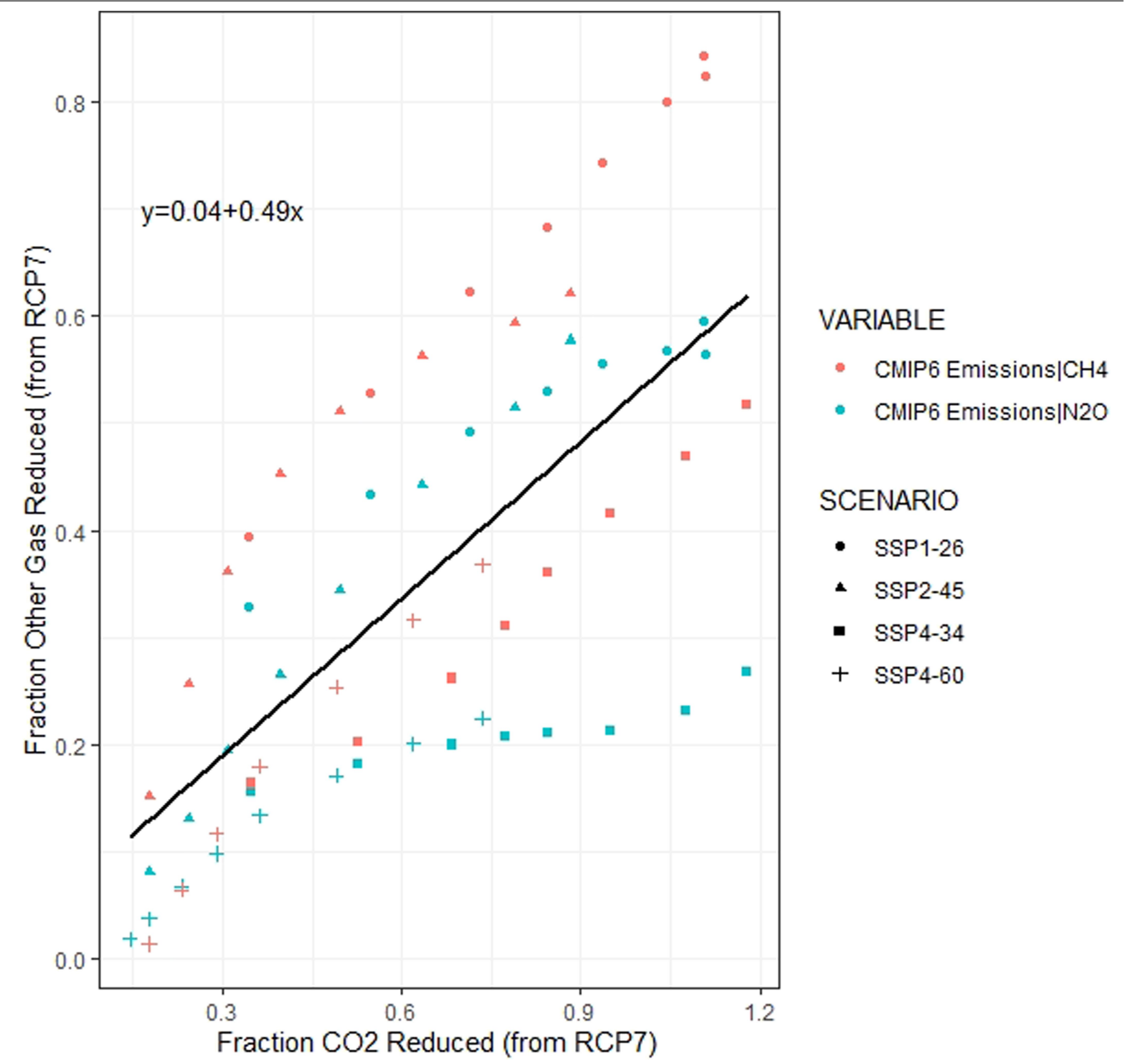

Extended Data Fig. 6 | Relationship between fractional reductions in $\mathrm{CO}_{2}$ from $\mathrm{RCP} 7$ and fractional reductions in $\mathrm{CH}_{4}$ and $\mathrm{N}_{2} \mathrm{O}$ based on emissions exogenous forcing term in the climate model that parameterizes forcing from from the SSP Database. The fitted relationship is used to scale the non- $\mathrm{CO}_{2}$ greenhouse gases. 


\section{Article}

Extended Data Table 1 | Parameter values used to highlight tipping points and thresholds used for model runs shown in Fig. 2 in main text

\begin{tabular}{|c|c|c|c|c|}
\hline & Parameter & $\begin{array}{c}\text { Figure } 2 a \\
\text { (Individual Behavior } \\
\text { Change) }\end{array}$ & $\begin{array}{c}\text { Figure } 2 \mathrm{~b} \\
\text { (Learning by Doing) }\end{array}$ & $\begin{array}{c}\text { Figure 2c } \\
\text { (Perception } \\
\text { Feedback) }\end{array}$ \\
\hline \multirow[t]{7}{*}{ Opinion } & Network Homophily & 0.7 & 0.75 & 0.95 \\
\hline & $\begin{array}{l}\text { Initial Fraction } \\
\text { Opposed }\end{array}$ & 0.2 & Varied & 0.26 \\
\hline & $\begin{array}{l}\text { Initial Fraction } \\
\text { Neutral }\end{array}$ & 0.6 & 0.5 & 0.33 \\
\hline & Persuasive Force & 0.2 & 0.3 & 0.2 \\
\hline & Policy-Opinion Effect & 0 & 0 & 0 \\
\hline & Evidence Effect & 0 & 0 & Varied \\
\hline & $\begin{array}{l}\text { Credibility-Enhancing } \\
\text { Display Effect }\end{array}$ & Varied & 0 & 0 \\
\hline \multirow[t]{3}{*}{ Adoption } & $\begin{array}{l}\text { Perceived-Behavioral } \\
\text { Control Midpoint }\end{array}$ & -0.5 & 0 & 0 \\
\hline & $\begin{array}{l}\text { Perceived-Behavioral } \\
\text { Control Steepness }\end{array}$ & 1.5 & 2 & 2 \\
\hline & $\begin{array}{l}\text { Opinion-Adoption } \\
\text { Effect }\end{array}$ & Varied & 0.5 & 0.5 \\
\hline \multirow[t]{2}{*}{ Policy } & $\begin{array}{l}\text { Political Interest } \\
\text { Feedback }\end{array}$ & 5 & 0 & 3 \\
\hline & Status-Quo Bias & 1.5 & Varied & 1.5 \\
\hline \multirow[t]{4}{*}{ Emissions } & Max Mitigation Rate & 0.035 & 0.025 & 0.08 \\
\hline & $\begin{array}{l}\text { Learning by Doing } \\
\text { Feedback }\end{array}$ & 0.2 & Varied & 0.1 \\
\hline & Lag Time & 10 & 10 & 10 \\
\hline & $\begin{array}{l}\text { Temp-Emissions } \\
\text { Feedback }\end{array}$ & 0 & 0 & 0 \\
\hline \multirow[t]{2}{*}{ Cognition } & Shifting Baselines & 0 & 0 & Varied \\
\hline & Biased Assimilation & 0 & 0 & Varied \\
\hline
\end{tabular}


Extended Data Table 2 | Sensitivity of 2091-2100 Temperatures $\left({ }^{\circ} \mathrm{C}\right.$ relative to $1880-1910$ baseline) to alternate modelling choices

\begin{tabular}{|c|c|c|c|}
\hline & $\begin{array}{c}\text { As Reported in Table 2, Main } \\
\text { Manuscript Text } \\
\text { (1) }\end{array}$ & (2) & (3) \\
\hline Climate Model: & DICE 2013 & DICE 2013 & MAGICC v.7.5.3 \\
\hline Non- $\mathrm{CO}_{2}$ Forcers: & $\begin{array}{l}\text { Forcing Scaled Based on SSP- } \\
\text { RCP (Supplementary Figure 4) }\end{array}$ & No Reduction & $\begin{array}{l}\text { Emissions Scaled Based on SSP- } \\
\text { RCP (Supplementary Figure 4) }\end{array}$ \\
\hline Modal Pathway & 2.3 & 2.6 & $\begin{array}{c}2.4 \\
(1.9-3.4) \\
\end{array}$ \\
\hline Aggressive Action & 1.8 & 2.1 & $\begin{array}{c}2.0 \\
(1.6-2.8) \\
\end{array}$ \\
\hline $\begin{array}{l}\text { Technical } \\
\text { Challenges }\end{array}$ & 3.0 & 3.2 & $\begin{array}{c}3.0 \\
(2.4-4.2) \\
\end{array}$ \\
\hline $\begin{array}{l}\text { Delayed } \\
\text { Recognition }\end{array}$ & 3.1 & 3.2 & $\begin{array}{c}3.1 \\
(2.4-4.2) \\
\end{array}$ \\
\hline Little and Late & 3.6 & 3.6 & $\begin{array}{c}3.5 \\
(2.8-4.7) \\
\end{array}$ \\
\hline
\end{tabular}

Column (1) shows temperatures reported in Table 2 of the main paper which use an annualized version of the DICE 2013 climate model (as implemented in the coupled climate-social model used to generate emissions scenarios) and scales non- $\mathrm{CO}_{2}$ radiative forcing based on a relationship derived from the SSP-RCP scenarios (Extended Data Fig. 6). Column (2) shows the effect of fixing radiative forcing from non- $\mathrm{CO}_{2}$ greenhouse gases. Column (3) shows the effect of using the MAGICC v.7.5.3 climate mode ${ }^{94,103,104}$ instead. Reported temperature change is the median value from 100 Monte Carlo runs and the values in parentheses show the range across the 100 samples.

Note an important distinction between runs using the DICE climate model and MAGICC is that in the former, radiative forcing from non- $\mathrm{CO}_{2}$ forcers is scaled directly whereas in the latter, emissions of these forcers are scaled. Non- $\mathrm{CO}_{2}$ forcing is relatively more important in the low $\mathrm{CO}_{2}$-emissions scenarios, particularly Aggressive Action. 


\section{nature portfolio}

Corresponding author(s): Frances C. Moore

Last updated by author(s): Dec 14, 2021

\section{Reporting Summary}

Nature Portfolio wishes to improve the reproducibility of the work that we publish. This form provides structure for consistency and transparency

in reporting. For further information on Nature Portfolio policies, see our Editorial Policies and the Editorial Policy Checklist.

\section{Statistics}

For all statistical analyses, confirm that the following items are present in the figure legend, table legend, main text, or Methods section.

n/a Confirmed

Х $\square$ The exact sample size $(n)$ for each experimental group/condition, given as a discrete number and unit of measurement

Х $\square$ A statement on whether measurements were taken from distinct samples or whether the same sample was measured repeatedly

$\triangle \square$ The statistical test(s) used AND whether they are one- or two-sided

X Only common tests should be described solely by name; describe more complex techniques in the Methods section.

Х $\square$ A description of all covariates tested

Х $\square$ A description of any assumptions or corrections, such as tests of normality and adjustment for multiple comparisons

$\triangle$ A full description of the statistical parameters including central tendency (e.g. means) or other basic estimates (e.g. regression coefficient)

$\bigotimes$ AND variation (e.g. standard deviation) or associated estimates of uncertainty (e.g. confidence intervals)

Х For null hypothesis testing, the test statistic (e.g. $F, t, r$ ) with confidence intervals, effect sizes, degrees of freedom and $P$ value noted

$X$ Give $P$ values as exact values whenever suitable.

Х $\square$ For Bayesian analysis, information on the choice of priors and Markov chain Monte Carlo settings

Х $\square$ For hierarchical and complex designs, identification of the appropriate level for tests and full reporting of outcomes

Х $\square$ Estimates of effect sizes (e.g. Cohen's d, Pearson's $r$ ), indicating how they were calculated

Our web collection on statistics for biologists contains articles on many of the points above.

\section{Software and code}

Policy information about availability of computer code

Data collection No software was used for data collection

Data analysis Model was developed using the open-source software R (version 3.6.3). Model behavior and output was analyzed using R and R packages ggplot2 (version 3.3.5), tidyverse (version 1.3.1), randomForest (version 4.6) and randomForestExplainer (version 0.10.1)

For manuscripts utilizing custom algorithms or software that are central to the research but not yet described in published literature, software must be made available to editors and reviewers. We strongly encourage code deposition in a community repository (e.g. GitHub). See the Nature Portfolio guidelines for submitting code \& software for further information.

\section{Data}

Policy information about availability of data

All manuscripts must include a data availability statement. This statement should provide the following information, where applicable:

- Accession codes, unique identifiers, or web links for publicly available datasets

- A description of any restrictions on data availability

- For clinical datasets or third party data, please ensure that the statement adheres to our policy 


\section{Field-specific reporting}

Please select the one below that is the best fit for your research. If you are not sure, read the appropriate sections before making your selection.
Life sciences
Behavioural \& social sciences
Ecological, evolutionary \& environmental sciences

For a reference copy of the document with all sections, see nature.com/documents/nr-reporting-summary-flat.pdf

\section{Behavioural \& social sciences study design}

All studies must disclose on these points even when the disclosure is negative.

$\begin{array}{ll}\text { Study description } & \text { Development of a system dynamics model of the coupled climate-social system based on feedback behavior documented in the } \\ \text { literature across a range of relevant disciplines }\end{array}$

Research sample Calibration of the opinion and policy component uses data on climate change opinion in seven OECD countries between 2013 and 2020 from the Pew Research Group available at https://www.pewresearch.org/fact-tank/2020/10/16/many-globally-are-asconcerned-about-climate-change-as-about-the-spread-of-infectious-diseases/. This is the only time-series of public opinion on climate change available for more than 1-2 countries. This is matched with data on carbon pricing for the same set of countries over the same time period from the World Bank Carbon Pricing Dashboard (https://carbonpricingdashboard.worldbank.org/). This gives explicit carbon prices (i.e. emissions trading prices and carbon taxes). Ideally we would also incorporate information on shadow carbon prices arising from climate policies other than market-based approaches, but this information is not available. Parameters in the emissions component was calibrated based on an empirical estimate in Andersson (2019) "Carbon Taxes and CO2 Emissions: Sweden as a Case Study" on the effect of Swedish carbon prices on emissions. Sweden is a useful case for this application because it has had very high carbon prices for several decades, and because an estimate of the cumulative effect of these carbon prices on national emissions is available in the literature, which is required for this calibration.

Sampling strategy NA

Data collection Publicly available data sources were used to calibrate the model as described in the research sample. They are provided as part of the code repository.

Timing

Data was collected from the online repositories in November 2021

Data exclusions

No data was excluded from the analysis

Non-participation

NA as no primary data was included in the study

Randomization

NA as this is a modeling study

\section{Reporting for specific materials, systems and methods}

We require information from authors about some types of materials, experimental systems and methods used in many studies. Here, indicate whether each material, system or method listed is relevant to your study. If you are not sure if a list item applies to your research, read the appropriate section before selecting a response.

\begin{tabular}{l|l} 
Materials \& experimental systems \\
\hline$n / a$ & Involved in the study \\
\hline & $\square$ Antibodies \\
\hline & $\square$ Eukaryotic cell lines \\
$\square$ & $\square$ Palaeontology and archaeology \\
$\square$ & $\square$ Animals and other organisms \\
$\square$ & $\square$ Human research participants \\
$\square$ & $\square$ Clinical data \\
$\square$ & $\square$ Dual use research of concern
\end{tabular}

Methods $\mathrm{n} / \mathrm{a}$ Involved in the study

$\bigotimes \square$ ChIP-seq

\ $\square$ Flow cytometry

$\bigotimes \square$ MRI-based neuroimaging 